\title{
Evaluation of a Non-Cyanide Gold Plating Process for Switch Tubes
}

\author{
David P. Norwood, F. Edward Martinez
}

\section{Prepared by}

Sandia National Laboratories

Albuquerque, New Mexico 87185 and Livermore, California 94550 for the United States Department of Energy under Contract DE-AC04-94AL85000

Approved for public release; distributition is unlimited.

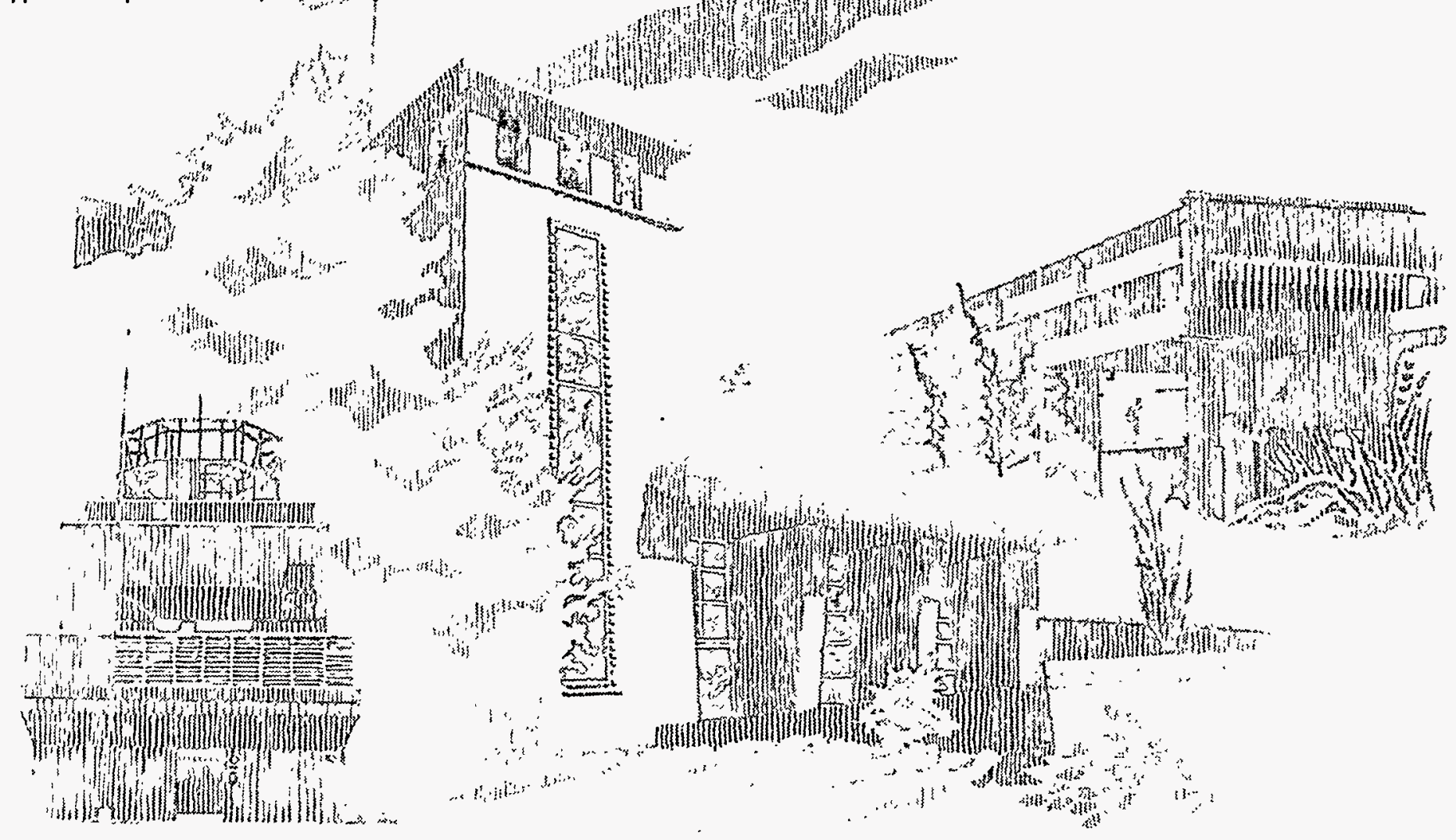


Issued by Sandia National Laboratories, operated for the United States Department of Energy by Sandia Corporation.

NOTICE: This report was prepared as an account of work sponsored by an agency of the United States Government. Neither the United States Government nor any agency thereof, nor any of their employees, nor any of their contractors, subcontractors, or their employees, makes any warranty, express or implied, or assumes any legal liability or responsibility for the accuracy, completeness, or usefulness of any information, apparatus, product, or process disclosed, or represents that its use would not infringe privately owned rights. Reference herein to any specific commercial product, process, or service by trade name, trademark, manufacturer, or otherwise, does not necessarily constitute or imply its endorsement, recommendation, or favoring by the United States Government, any agency thereof or any of their contractors or subcontractors. The views and opinions expressed herein do not necessarily state or reflect those of the United States Government, any agency thereof or any of their contractors.

Printed in the United States of America. This report has been reproduced directly from the best available copy.

Available to DOE and DOE contractors from

Office of Scientific and Technical Information

PO Box 62

Oak Ridge, TN 37831

Prices available from (615) 576-8401, FTS 626-8401

Available to the public from

National Technical Information Service

US Department of Commerce

5285 Port Royal Rd

Springfield, VA 22161

NTIS price codes

Printed copy: A03

Microfiche copy: A01 
SAND 95-3065

Distribution

Unlimited Release

Printed January 1996

Category UC-704

\title{
EVALUATION OF A NON-CYANIDE GOLD PLATING PROCESS FOR SWITCH TUBES
}

\author{
David P. Norwood \\ and \\ F. Edward Martinez \\ Electronic Processing Department \\ Sandia National Laboratories \\ Albuquerque, NM 87185-0957
}

\begin{abstract}
Switch tubes are used in nuclear weapon firing sets and are required to be reliable and impervious to gas permeation for many years. To accomplish this, a gold plated coating of approximately 25 microns is required over all metal surfaces on the tube exterior. The gold has historically been plated using gold cyanide plating chemistry. In this work we proposed to replace the cyanide plating bath with an environmentally friendlier sulfite gold plating bath. Low and high pH sulfite plating chemistries were investigated as possible replacements for the cyanide gold plating chemistry. The low pH plating chemistry demonstrated a gold plated coating which met the high purity, grain size, and hardness requirements for switch tubes. The high $\mathrm{pH}$ chemistry was rejected primarily because the hardness of the gold plated coatings was too high and exceeded switch tube coating requirements. A problem with nodule formation on the gold plated surface using the low pH chemistry had to be resolved during this evaluation. The nodule formation was postulated to be produced by generation of $\mathrm{SO}_{2}$ in the low pH bath causing gold to be precipatated out when the sulfite concentration falls below a minimum level. The problem was resolved by maintaining a higher sulfite concentration and providing an active filtration system during plating. In this initial study, there were no major obstacles found when using a sulfite gold bath for switch tube plating, however, further work is needed on bath control and bath life before adopting it as the primary plating chemistry.
\end{abstract}

\section{MASTER}


This work performed at Sandia National Laboratories supported by the U.S. Department of Energy under contract DE-AC04-94AL-85000.

\section{Contents}

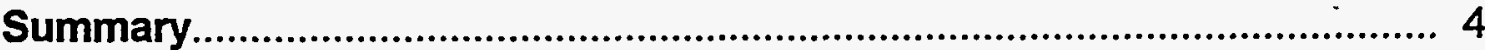

Switch Tubes ............................................................................................ 5

Switch Tube Processing

Plating Bath Chemistry

Cyanide Gold Plating Baths

Sulfite Gold Plating Baths

Sulfite Gold Plating Bath Candidates

Preliminary Evaluation.

Test Samples

Cyanide Gold Properties

SNL/NM Cyanide Gold Plating

Sulfite Evaluation Planning.

Initial Sulfite Gold Plating Evaluation

Plating Parameters and Setup

Initial Gold Plating Results

Sulfite Gold Plating Bath Selection

Gold Plating Problems.

Voids

Material Compatibility

Nodules and Slivers

TG25E Sulfite Bath Filtering Experiment

Step Test Evaluation

Step Test Procedure

Test for Nodules Using the Step Test

Nodule Formation.

Filtering During Gold Plating

Sulfite Gold Plated Coatings.

Coating Thickness

Current Density

Sulfite Plating Bath Life.

Depletion Test

Depletion Testing

Restoring a Sulfite Gold Plating Bath

Switch Tube Plating.

Initial Switch Tube Plating

Final Switch Tube Plating

Acknowledgements 


\section{Figures}

1. Photograph of Unplated Switch Tube

2. Outline of Switch Tube Plating Process

3. Sketch of Test Sample Used in Plating Study

4. Plated Gold Thickness of SNL vs. Vendor Cyanide Bath Plating

5. Plated Gold Hardness of SNL vs. Vendor Cyanide Bath Plating

6. Cross Section of Gold Plated Braze Joint Using Cyanide Bath Plating

7. Planning for Sulfite Gold Plating Evaluation

8. Metallurgical Cross Section Showing Voids in a Brazed Joint on Test Sample Number 10. The Test Sample Was Gold Plated in a Cyanide Gold Plating Bath.

9. Photomicrograph of Nodules Produced by Sulfite Gold Plating Bath TG25E

10. Photomicrograph of Gold Nodules on Plated Surface of Test Sample. Gold Plated Using TG25E (Filtered) Gold Bath

11. Step Test Panel After Plating Using the Step Test Procedure

12. Photos of Gold Coatings on a Step Panel Which Show the Formation of Nodules During Plating in a TG25E Sulfite Gold Plating Bath

13. Graph of Nodule Quantities and Sizes Which are Formed During Sulfite Gold Plating

14. SEM Photo of Particles Trapped in Filter Paper Used to Filter Sulfite Gold Plating Bath

15. Element Analysis Particles Suspended in Sulfite Gold Plating Bath

16. Diagram of Active Filtration System Used for Sulfite Gold Plating Bath

17. Electroplating Efficiency of Sulfite TG25E Gold Plating Bath C

18. Gold Content of TG25E Sulfite Gold Plating Bath $C$ by Plating Run

19. Electroplating Efficiency of Sulfite TG25E Gold Plating Bath D

20. A Switch Tube Which Has Been Prepared for Plating

21. Microphoto of a Switch Tube Braze Joint After Sulfite Gold Electroplating

22. Microphoto of a Cross-Sectioned Switch Tube After Sulfite Gold Electroplating in the Actively Filtered Plating Bath

\section{Tables}

1. Test Results on Gold Coatings Plating in Vendor Cyanide Bath

2. Summary of Properties for Cyanide Plated Gold Coatings

3. TG25 and TG25E Sulfite Gold Plating Bath Comparisons

4. Gold Properties of Sulfite and Cyanide Plated Coatings

5. Range of Film Thicknesses for Vendor vs. SNL Plated Coatings

6. Properties of Gold Coatings Plated at Moderate and High Current Density in TG25E Gold Sulfite Plating Bath

7. Measured Properties of Plating Bath D After Adjustment

8. Gold Thickness Measurements on a Switch Tube Plated in TG25E Sulfite Plating Bath Having a Gold Content of 1.0 Troy Oz. per Gal. 


\section{SUMMARY}

Switch tubes (sprytrons) are used in nuclear weapon firing sets to provide a high voltage (kV), high current $(\mathrm{kA})$ triggered discharge of capacitors into detonators and neutron generators. The tubes are designed to be reliable for many years and, as such, are required to be impervious to gas permeation through the Fe-Ni alloy structural components. Gold plating is required to a minimum thickness of $\mathbf{2 5}$ microns over all metal surfaces on the tube exterior to ensure this sealing of the tube. The gold has historically been plated using a cyanide plating bath chemistry. It is this feature which was of interest in this development work. We proposed to replace the cyanide plating bath with an environmentally friendlier sulfite gold plating bath which was less hazardous to personnel. Technic Inc. promoted their sulfite plating baths as a replacement for the cyanide types, and their Techni-Gold $25 \mathrm{E}$ was used as the primary replacement bath for the cyanide gold bath in this study.

Technic Inc. supplies two sulfite bath chemistries which are a Techni-Gold 25 and a Techni-Gold 25E. The Techni-Gold 25 operates at a pH of 9.0 to 10.0 while the Techni-Gold 25E operates at a pH of 6.0 to 7.0. The Techni-Gold $25 \mathrm{E}$ is more attractive as a replacement for cyanide gold chemistries due to the neutral pH operating range. Also, the Techni-Gold 25 does not meet the Grade A (90 Knoop Maximum hardness) requirement. Grade A gold deposits are specified on switch tube drawings. Both the vendor cyanide gold and the Techni-Gold 25E meet this specification, while the Technic-Gold $25 E$ is slightly softer when plating from a new bath chemistry. Other resultant properties of the gold deposits from either bath chemistry proved to be quite comparable. Good, comparable adhesion was realized from both the cyanide and sulfite gold deposits using Sebastian adhesion test methods. The grain size for the cyanide gold deposit was negligibly smaller than that of the sulfite gold deposit. The cyanide gold deposit was somewhat more lustrous than the sulfite gold deposit. Finally, uniformity of the deposit thicknesses from both cyanide and sulfite bath chemistries compared favorably to each other, and the $\mathbf{2 5}$ micron thickness requirement was easily achieved by each.

Nodule formation, when plating thick gold deposits using the Techni-Gold 25E, proved to be somewhat problematic. After bath analysis and deposit metallography, the nodule problem was resolved by real-time active solution filtration, increasing the conducting salt concentration, and increasing the gold concentration in the bath chemistry. Sample pretreatment and the coatings plated prior to final gold plating did not influence the formation of nodules.

Data was generated in this study to determine the minimum gold concentration allowable to produce acceptable gold deposits. This was accomplished through a series of gold concentration depletion tests. A final outcome from this phase of the study was a restoration method for a "spent" bath. This restored, sulfite gold plating bath resulted in a gold plating efficiency which is comparable to that of a new bath.

There are two aspects of this sulfite plating evaluation which are in need of further investigation. The first is more of an in-depth analysis of the sulfite bath chemistry and control parameters of the bath to ensure good plating deposits. The second aspect is that the evaluation showed evidence of porosity and/or pinholes on the braze areas. Since these do not appear on any other significant surfaces, it is assumed that the cause is in the braze material and not in the plating process or final plated coating. Time and funding constraints did not allow these issues to be addressed properly. Future work addressing these issues should be considered. 


\section{SWITCH TUBES}

Switch tubes (sprytrons) are used in nuclear weapon firing sets to provide a high voltage (kV), high current (KA) triggered discharge of capacitors into detonators and neutron generators. The tube contains an anode, cold cathode, and trigger. The tubes are designed to be reliable for many years in hostile environments. They vary in size, but most are slightly larger than a thimble. They are constructed of ceramics and metals for ruggedness, durability, and quality considerations. Sprytrons are required to be hermetically sealed to preserve the vacuum inside the tube and prevent gas permeation. The tube is sealed by brazing together ceramic and metal subassemblies, laser welding the subassemblies to one another, and pinching off (cold welding) a copper tube used to evacuate the assembly. A photo of a switch tube is shown in Figure 1, and this is the model used in this evaluation.

A major quality consideration is that the switch tube be impervious to gas permeation through the $\mathrm{Fe}-\mathrm{Ni}$ alloy structural components. Fe-Ni (commonly called kovar) is susceptible to $\mathrm{H}_{2}$ permeation, particularly during the high-temperature $\left(600^{\circ} \mathrm{C}\right)$ bakeout prior to exhaust. Gold plating prior to bakeout prevents the kovar from "loading up" with $\mathrm{H}_{2}$ during bakeout. It is believed this $\mathrm{H}_{2}$ doesn't get pumped out during evacuation. There are also concerns that $\mathrm{H}_{2}$ could permeate through the kovar during stockpile life, but this problem is mostly mitigated by the tin-lead solder coating applied after bakeout. The gold plating is thick by plating standards in that it is required to be a minimum of $\mathbf{2 5}$ microns over all metal surfaces on the tube exterior. The gold is historically plated using a cyanide plating bath chemistry. It is this feature which was of interest in this development work; we proposed to replace the cyanide plating bath with an environmentally friendlier sulfite gold plating bath which was also less hazardous to personnel.

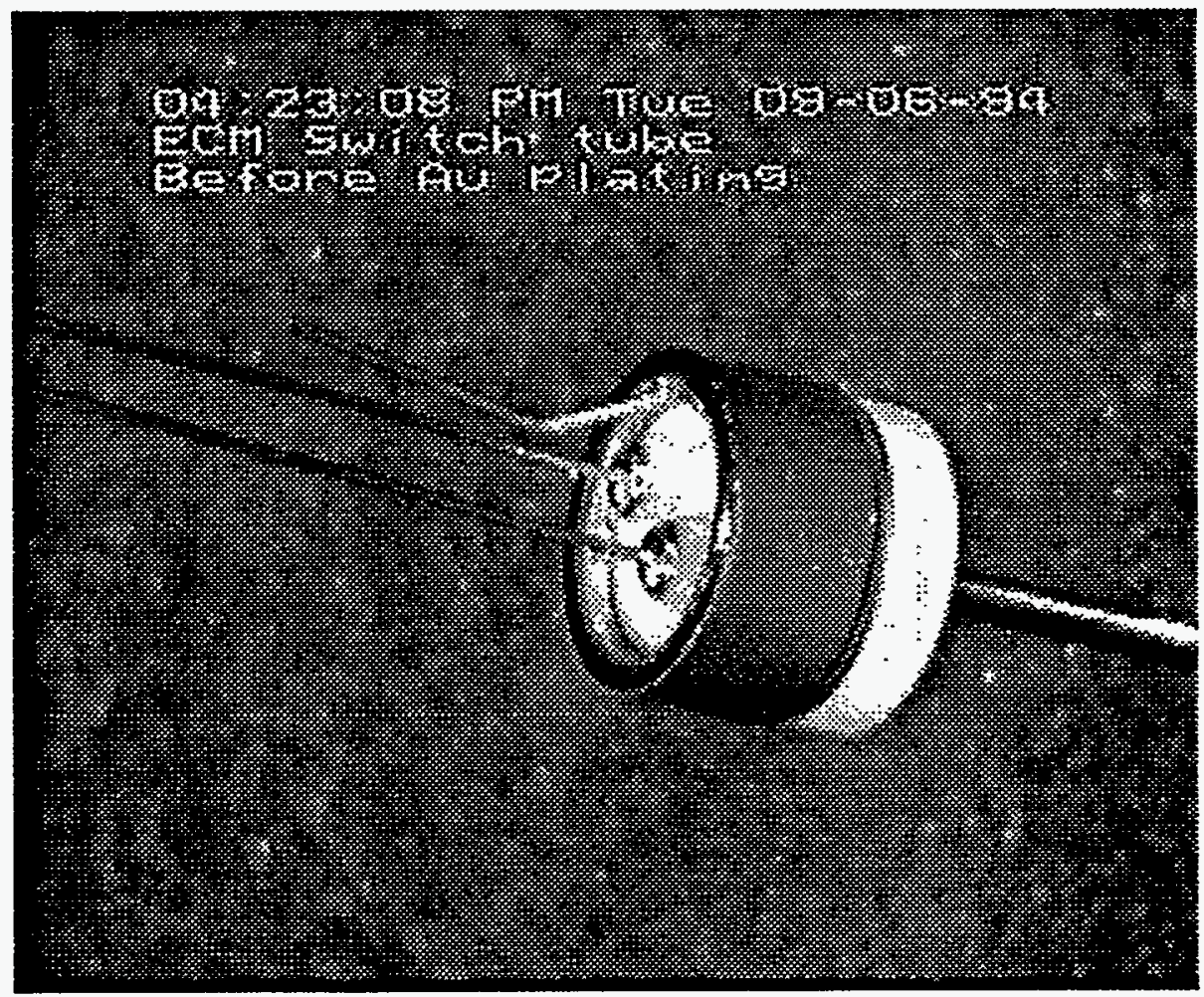

Figure 1. Photograph of Unplated Switch Tube 


\section{Switch Tube Processing}

The gold plating operation on switch tubes occurs after the envelope of the tube is fully assembled. The tube is not sealed after final assembly but remains open by way of a small copper pipe extending out the top. This copper pipe allows testing of the sprytron seal integrity and permits evacuation of the sprytron prior to final sealing (pinch off of the copper pipe). A final operation in switch tube processing is to gold plate all metal exposed on the outside tube envelope. These metals include copper, kovar, and braze material. These metals must be cleaned, pre-plated with base metals, and then gold plated to the proper thickness. During the plating process, it is necessary to fixture the switch tube to prevent entry of any solutions into the switch tube cavity. The fixturing also provides electrical connection to all the switch tube metal parts for electroplating operations. An outline of the plating process is shown in Figure 2.

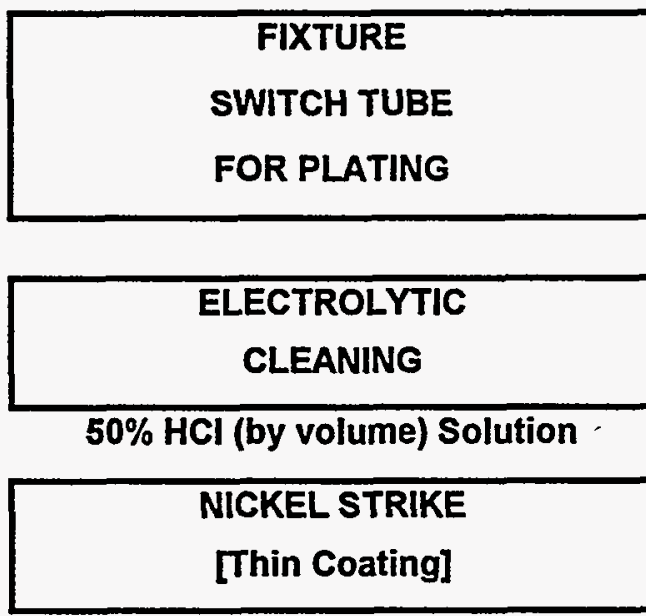

Step 1

Woods Nickel Strike Bath

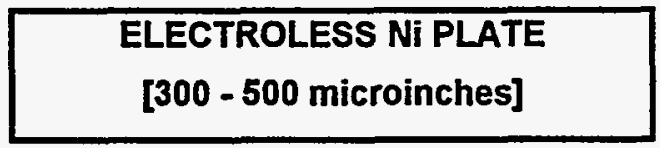

Step 2

Boron E Electroless Ni Bath

\begin{tabular}{c}
$\begin{array}{c}\text { GOLD PREPLATE } \\
\text { [Thin Coating] }\end{array}$ \\
\hline
\end{tabular}

Step 3

Orotemp C Au Electroplating Bath

FINAL GOLD ELECTROPLATE
[ 25 Microns (1 mil)]

Step 4

Orotemp 24 Au Electroplating Bath

NICKEL OVERPLATE
[Thin Coating]

Step 7

Watts Nickel Electroplating Bath

Figure 2. Outline of Switch Tube Plating Process 
A general description of switch tube plating process is given here. More detailed information on plating bath characteristics and their operation is given later in this report. This processing was established early in switch tube development and has served well to provide a reliable, adherent coating for the switch tube exterior. As described previously, the initial step for plating is to fixture the switch tube for plating operations. Openings to the tube cavity are sealed, and all conductive parts of the tube are interconnected in the fixturing operation. The tube is then electrolytically cleaned using 50 percent solution (by volume) of hydrochloric acid. This cleaning removes any oils, greases, or residues as a result of fixturing or handling. The next step is to electroplate an adhesion coating of nickel in preparation for further plating operations. A second nickel coating is plated using an electroless nickel bath to increase the nickel thickness to 300 to 500 microinches. This thicker nickel coating ensures that all the metal surfaces are sealed and ready to accept the gold plating which occurs next. Before final gold plating, a thin coating of gold is electroplated on the metal surfaces in a preplate operation. It would be possible to go directly into the final gold electroplate bath; however, using a preplate gold bath ensures that any chemicals or elements on the switch tube surface that might contaminate a gold bath are removed or coated over in the less expensive preplate gold bath. Contamination of gold plating baths with a high gold concentration can be very costly. The exterior gold coating of the switch tube is then electroplated in the final gold bath to a minimum thickness of $\mathbf{2 5}$ microns. Finally, nickel is electrodeposited over the 25 micron gold to accommodate soldering operations in the next assembly. The plating operations, as described, are used at the vendor's plating facility in the manufacture of switch tubes and were also used at Sandia Labs to establish a baseline for sulfite gold plating.

\section{PLATING BATH CHEMISTRY}

The intent of this study was to determine if a direct substitution of the cyanide plated gold coatings could be replaced by sulfite plated gold coatings. A description of the plating baths used in the evaluation is given here as well as the reasons candidate sulfite plating baths were selected.

\section{Cyanide Gold Plating Baths}

Historically, cyanide gold plating has been widely used for high purity deposits in the electronic industry for a variety of applications. The high alkalinity and the cyanide ingredient, in the cyanide gold bath chemistry, contribute to excellent adhesion properties of the gold deposits on a variety of substrate materials. The alkaline, neutral, and acid gold baths, shown below, contain cyanide in varying degrees, while the non-cyanide category contain no cyanide and primarily includes the sulfite chemistries. Today, the sulfite chemistries are of particular importance due to their non-hazardous nature.

The chart below, Electrolyte Classification, shows some applications for the various chemistries. The alkaline, cyanide chemistries are primarily used for pure gold deposits and some alloy bright deposits. The neutral and acid cyanide chemistries are primarily used for bright alloy deposits with enhanced hardness. The non-cyanide (sulfite) chemistries are primarily used for thick, bright deposits of high purity with very limited use in alloy deposits. Until the last few years, sulfite chemistries were in the 10 to $12 \mathrm{pH}$ range. Recently some low pH $(\sim 6.0)$ sulfite chemistries have been developed which will greatly expand the use of these chemistries.

\section{Sulfite Gold Plating Baths}

Although the sulfite plating chemistry does not date back as far as the cyanide chemistry, it has been around for some time. They first were explored in the early 1960 s as possible replacement for cyanide baths without much success. Early attempts in the 1970 s to use this type bath for gold plating at Sandia Labs were somewhat successful but were not entirely fruitful due, primarily, to the difficulty in keeping the bath within chemistry limits. In a number of instances 


\section{Electrolyte Classification}

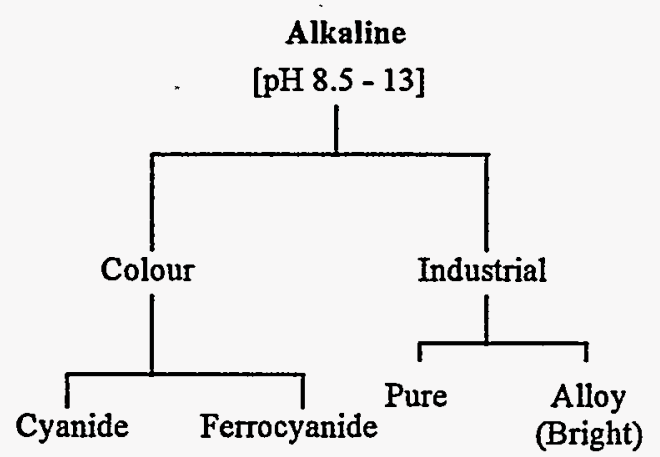

Acid

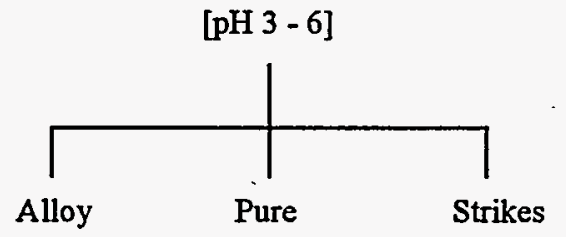

Neutral

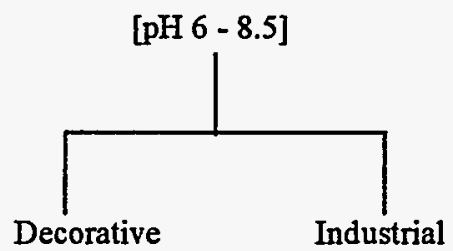

the bath would fail, resulting in the loss of gold with expensive downtime and reclamation costs. The primary problem with the sulfite chemistry at that time was the rapid increase of solution density due to the continual additions of conducting salts. Also, the gold would precipitate onto the walls of the plating vessel as well as the plumbing and heater surfaces.

\section{Sulfite Gold Plating Bath Candidates}

Before planning the research on this sulfite gold plating study, some cursory work was done to establish whether a good candidate plating bath existed. It was found there were two vendors who promoted their sulfite plating baths as a replacement for the cyanide types. In talks with the vendors, it was revealed that the chemistry had been improved and that most, if not all, of the problems with this type bath had been eliminated. The cost for these newer sulfite chemistries do not vary significantly from those with cyanide, because the major cost of either is in the precious metal and not in the related chemistry.

The gold sulfite complex contains two sulfite ions per gold ion. As indicated earlier, at high pH levels, sulfite ions accumulate in the solution as gold is replenished with subsequent specific gravity increase. This has been the major problem with gold sulfite plating baths in high speed or selective plating. Consequently, it is clearly advantageous to operate a sulfite gold solution under conditions that allows the sulfur dioxide to volatilize at somewhat the same rate that the gold is consumed. This would allow for the solution to be self-regulating, very much like the neutral and acid cyanide gold solutions. Technic Inc. has developed such a bath and is identified as "Techni-Gold 25E." This bath can be operated at a pH of 6.0 to 7.0 at $60^{\circ} \mathrm{C}$, which makes it ideal for plating printed circuit boards and hybrid microcircuits when organic resist masks are employed. Due to the anticipated general use for this type of chemistry, the Techni- 
Gold 25E was chosen for this study for possible replacement of the cyanide gold plating chemistry.

The deposits from the Techni-Gold 25E bath are in the hardness range of 60-70 Knoop. Unlike the higher $\mathrm{pH}$ sulfite gold systems, the addition of arsenic does not increase the hardness. Addition of an organic brightener does increase the hardness to about $160 \mathrm{Knoop}$ and the crystal orientation transforms from (100) to (111).

\section{PRELIMINARY EVALUATION}

The initial work in the sulfite plating research was concentrated on determining the properties of the gold coating which were needed to meet switch tube requirements. To accomplish this, a trip was made to the switch tube manufacturer; and samples were plated using the established cyanide plating techniques (as described in Figure 2). The samples were then analyzed to determine properties of the gold coating; and these were used as a baseline for the research on a sulfite plating bath replacement coating.

\section{Test Samples}

Test samples were prepared which exhibited the same type of surfaces which would be plated in switch tube processing. Switch tubes were not used as the evaluation vehicle because of the high costs involved and because coating analysis is better accomplished on a flat surface than the rounded surface of a switch tube. Consequently, test samples were fabricated on ceramic substrates which were $2 \times 2$ inches and 0.025 inch in thickness. A sketch of the test sample is given in Figure 3.

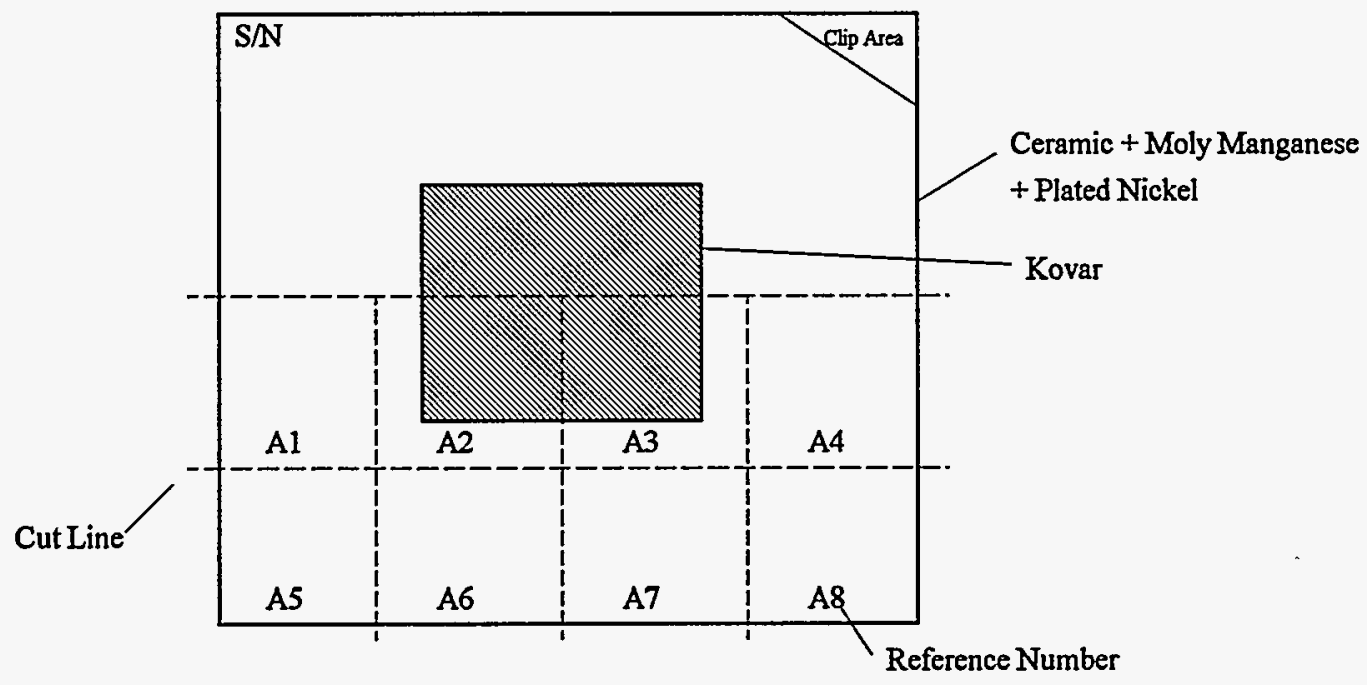

Figure 3. Sketch of Test Sample Used in Plating Study

The test sample included most of the materials which are used in switch tube construction. Ceramic ( $96 \%$ alumina), kovar, and copper braze material form the base material with coatings of moly manganese, nickel and copper being used in its assembly. A plating clip attachment area and serial number area are indicated to allow continuity in testing from sample to sample. To further establish continuity in the analysis of plated coatings, cut lines were preplanned (as shown on the sketch) to 
provide reference points. The reverse side of the sample was fabricated identically to the front side.

\section{Cyanide Gold Properties}

Two test samples (Serial Numbers 4 and 6) were plated at the vendor's facility using the same processes and baths as those used in switch tube plating. The samples were $2 \times 2$ inches and had the same materials' combination as found on the actual switch tubes. The nickel and gold plating baths, approximately 20 gallon each, are designed to accommodate simultaneous plating of several switch tubes. The process entails 1) Precleaning, 2) Acid activation, 3) Wood's nickel strike, 4) Electroless nickel plate, 5) Gold Strike, 6) Gold plate, and 7) Nickel plate with appropriated rinses between each of the plating processes. The two test samples did not receive the final nickel plate since it was the cyanide gold deposit that was to be analyzed for comparison to the sulfite gold deposit.

Plated test samples were returned to SNL/NM, and the coatings were studied with special attention being given to the plated gold. A visual inspection of the sample 4 (no nickel overplate) was made; and results showed the gold plating to be a uniform, bright and shiny coating with no voids or surface defects. Small nodules which typically occur on the surface of thick, plated coatings were minimal. Samples were cut into smaller parts approximately as shown in Figure 3. The smaller parts were then made into metallurgical samples for cross-sectional analysis. The metallurgical samples were studied for gold properties of thickness, grain size, hardness and adhesion. Gold thickness was studied for variations which might occur because of plating location and base material. Thickness analysis was performed on the nickel underlayer to provide additional data. The results of this analysis are given in Table 1.

The analysis showed the coatings plated using the gold, cyanide plating bath to be adherent, Grade A in hardness, and of small grain size. Gold thickness uniformity was the only property which was of some concern, having a range of about 2:1 over the total areas tested. However, switch tube requirements provide for a minimum thickness callout and a wide variation in thickness would only serve to increase the cost of processing. More gold would have to be plated to ensure the thinner plated areas are adequately coated. Adhesion data was obtained using a Sebastian pull test method. Sometimes described as a "nail head" test, a small diameter nail head is epoxied to the coating under test and pulled to destruction. The resultant pull strength is calculated in psi as determined from the nail head diameter. One of the problems with this test is that it is no better than the strength of the epoxy used and its adhesion strength to the coating. However, it does provide information on the relative adhesive strength of the coating and gives empirical data on pull strengths. Adhesion test results on the vendor gold coating were clouded as the epoxy failed, and limited data was obtained on its adhesive strength. Pull strengths ranged from 3,000 to 4,300 psi on both front and back side gold platings. Expected adhesive strength of gold coating would be in the tens of thousands of psi pull strength; however, the test proved that the adhesion was at least greater than that of the epoxy. 


\begin{tabular}{|c|c|c|c|c|}
\hline & \multicolumn{2}{|c|}{ Switch Tube Number 4} & \multicolumn{2}{|c|}{ Switch Tube Number 6 * } \\
\hline $\begin{array}{l}\text { Average } \\
\text { Thickness }\end{array}$ & Gold (Mils) & Nickel (mils) & $\begin{array}{l}\text { Gold } \\
\text { (Mils) }\end{array}$ & Nickel (mils) \\
\hline $\begin{array}{c}\text { Center Front } \\
\text { side }\end{array}$ & 1.74 & 0.50 & 0.80 & 0.83 \\
\hline $\begin{array}{l}\text { Center Back } \\
\text { side } \\
\end{array}$ & 1.63 & 0.51 & 0.82 & 0.81 \\
\hline Edge Front side & 2.05 & 0.91 & 1.35 & 1.10 \\
\hline Edge Back side & 2.16 & 0.93 & 1.65 & 1.05 \\
\hline \multicolumn{5}{|r|}{$\begin{array}{l}\text { * } \mathrm{Ni} \\
\text { Overplate }\end{array}$} \\
\hline Gold Properties & Frontside & Backside & Frontside & Back side \\
\hline Adhesion (psi) & 4,160 & 4,280 & - & - \\
\hline Au Hardness* & 55.6 & 55.5 & - & - \\
\hline Au Grain Size ${ }^{\star \star}$ & - & - & 13.3 & - \\
\hline
\end{tabular}

\section{SNL/NM Cyanide Gold Plating}

The initial tests at SNL/NM were to set up an identical gold plating line to that of the vendor and replicate the cyanide gold plating results. The cyanide gold plating chemistry is a Orotemp 24 supplied by Technic, Inc. A similar but smaller plating line was established which included cleaning, nickel plating, and gold plating baths as described in Figure 2. Bath sizes were limited to laboratory quantities of 1 to 2 gallons of solution as opposed to the 5- to 10-gallon plating baths used at the vendor plating facility. This facilitated adjustment and would be less expensive if experiments resulted in contamination of the baths.

Identical test samples were gold plated in the SNL/NM facility to verify that our plated coatings were similar to those produced at the vendors using the same cyanide plating bath chemistry. The only differences in processing, other than bath size, were that a fixture was used to hold the $2 \times 2$ inch panel during nickel plating to increase the plating area, and the baths used at SNL were new as opposed to the older plating baths at the vendor facility. Vendor baths were approximately one year old. A few errors were made in plating the initial samples resulting in foxy brown gold; however, after getting over the learning curve, two test samples were plated without problems and were indicative of a good plating process. The samples were sectioned and metallurgical samples prepared to evaluate the gold coatings.

Plated gold thicknesses are compared in Figure 4 between SNL and vendor plating deposits. Coatings on test samples were measured on both front and back side as well as on the kovar and moly manganese surfaces. The thickness of the coatings are referenced to the 1 mil minimum thickness as required by switch tube specifications. Thickness data shows the SNL coatings to be comparable to the vendor coatings. Both coatings met thickness requirements with the exception of two SLN data points 
taken on the kovar and moly surfaces. The kovar is located in the center of the sample where thinner deposits typically occur. SNL gold plating was somewhat more uniform over the plated surfaces; and this could be attributed to a number of plating parameters, but non-uniformity is generally indicative of less plating solution agitation.

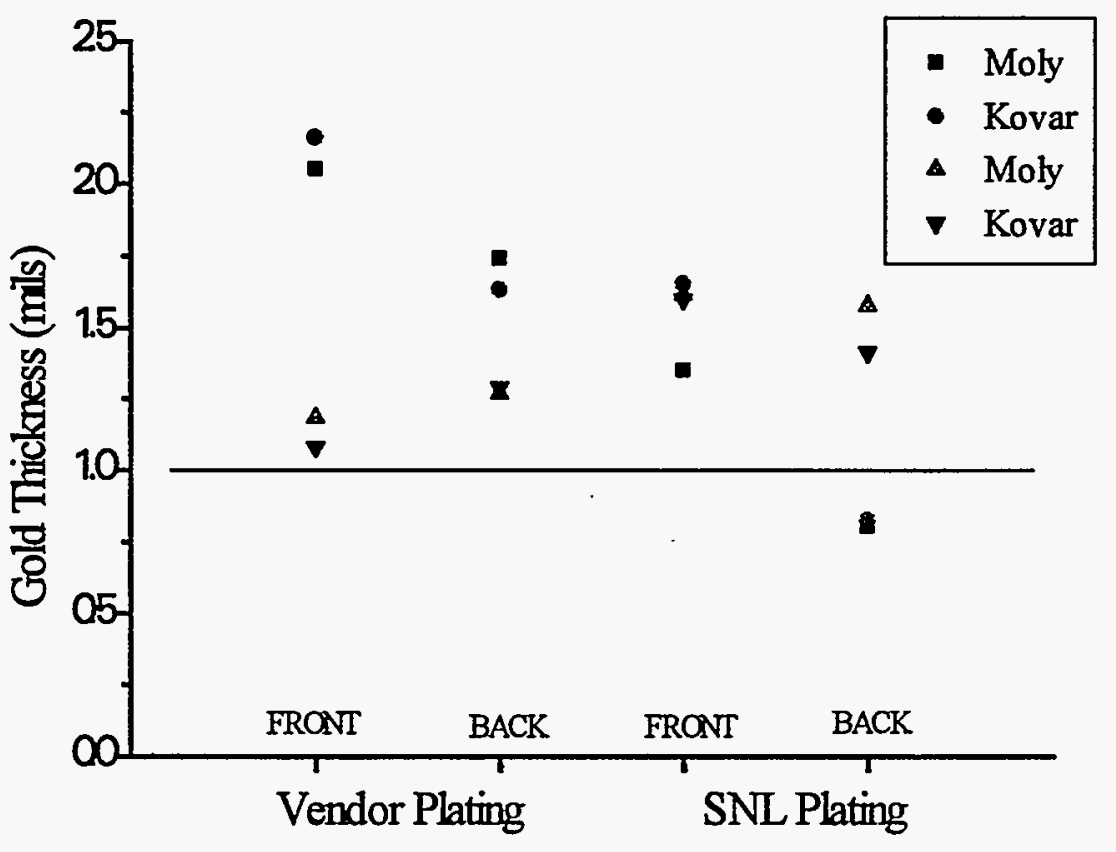

Figure 4. Plated Gold Thickness of SNLNM vs. Vendor Cyanide Bath Plating

Both SNL and Vendor plating deposits fell within the grade A range for gold plating as shown in Figure 5. Grade A gold is defined as exceptionally pure gold and has a Knoop value between 40 to 90 . The SNL deposit was slightly softer, averaging about 50 as compared to the vendor gold which averaged about 60 . The hardness of deposited gold will increase during use of a gold plating bath, and this difference is attributed to the age of the vendor plating bath.

Relative grain size of a gold coating can generally translate to hardness; the larger the grains the softer the coating and vice versa. No attempt was made, in this study, to achieve any particular hardness level for the various coatings. We looked at grain size only to determine if the gold sulfite deposits corresponded to those produced in the gold cyanide system.

Grain size measured 13.3 on the vendor gold plating and 13.3/15.5 on the SNL/NM gold plating (two samples were available for measurement on SNL processed coatings). Both coatings were measured at the same location on test samples and are an average over a relatively large area in the cross section of the coating. The results indicate a relatively small grain size and that SNL/NM and vendor coatings are comparable in the gold grain sizes deposited. 


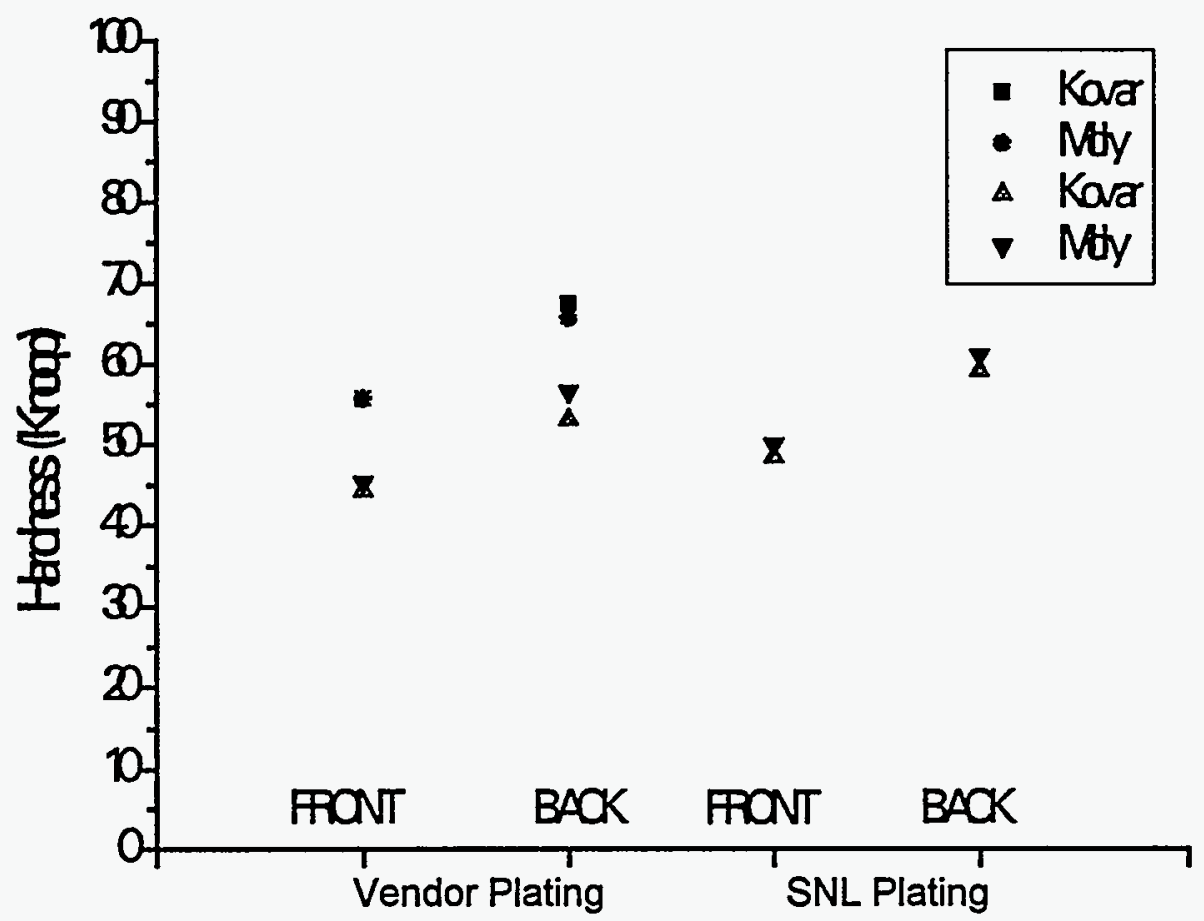

Figure 5. Plated Gold Hardness of SNL/NM vs. Vendor Cyanide Bath Plating

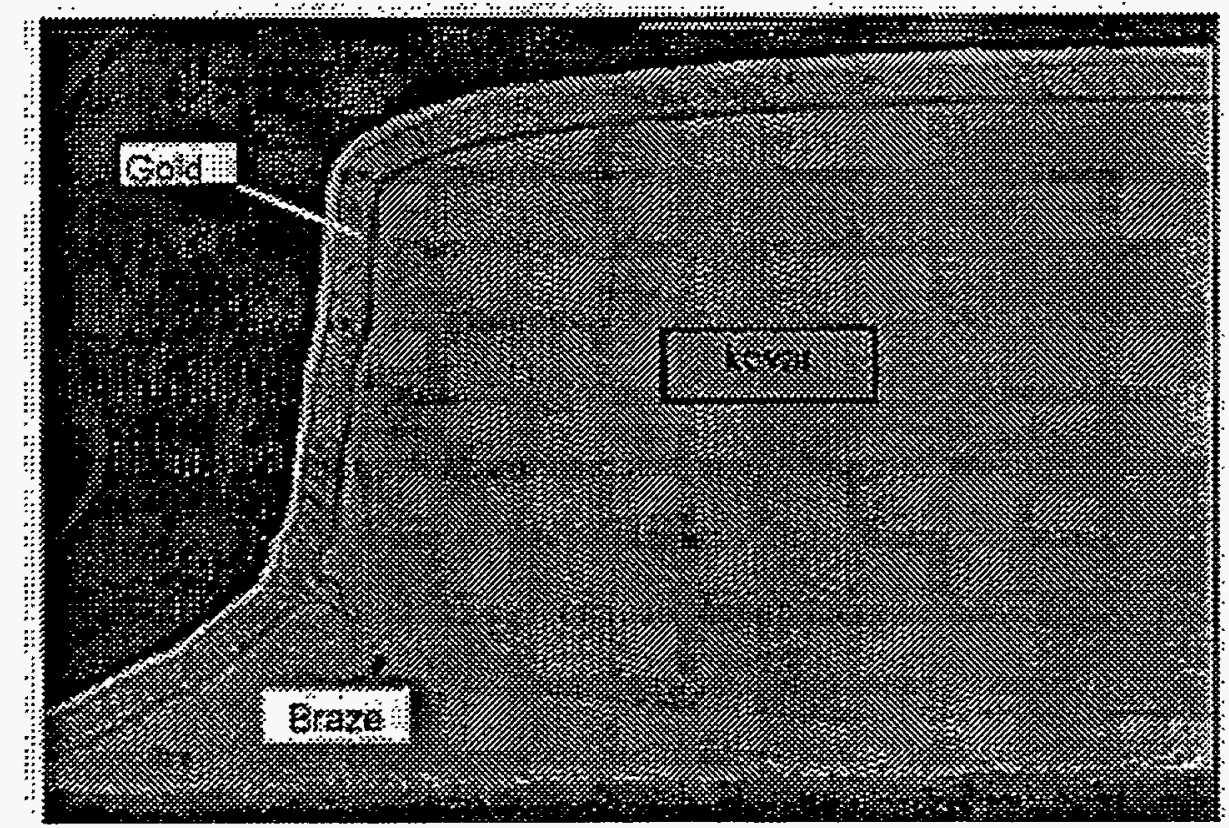

Figure 6. Cross Section of Gold Plated Braze Joint Using Cyanide Bath Plating $(80 X)$ 
Another property of the cyanide bath which is important is its throwing power. This is the property of the bath to coat nonuniform objects and to permit coating of recesses in the sample. The cyanide plating baths have historically been good at doing this. An assessment of throwing power can be obtained only by using cross sectional analysis of any recesses in the plated sample. The cyanide baths both performed well as can be seen in Figure 6. The exposed braze joint between the kovar and the moly coating represents a suface area which is subject to voids and irregularities and is difficult to plate. The microphotograph shows that this area was adequately coated with gold plating which extends into the voids apparent in the braze material.

In this section, we have presented data on the gold coatings produced by cyanide plating baths and then established the properties of the plated gold. Data was given on gold plating which was processed at both vendor and SNL/NM facilities. The data showed good correlation between the resultant coatings. Having established the properties needed in the gold films used in switch tube applications, the next phase of the study was to evaluate the sulfite plating baths as a replacement chemistry in producing them. A summary of plated gold properties using cyanide plating chemistry is given in Table 2, and these will be used as a baseline for comparison in the sulfite bath study.

\begin{tabular}{|l|c|c|}
\hline \multicolumn{1}{|c|}{ Au Property } & $\begin{array}{c}\text { Vendor Au } \\
\text { Coating }\end{array}$ & $\begin{array}{c}\text { SNL/NM Au } \\
\text { Coating }\end{array}$ \\
\hline \hline Hardness (Ave.) & 61.0 Knoop & 52.2 Knoop \\
\hline Grain Size & 13.3 & 13.9 \\
\hline Uniformity & $45.8 \%$ & $19.8 \%$ \\
\hline Adhesion on Moly Film & 3,015 psi & 7,054 psi \\
\hline Adhesion on Kovar & 4,220 psi & 10,504 psi- \\
\hline
\end{tabular}

Table 2. Summary of Properties for Cyanide Plated Gold Coatings

\section{SULFITE EVALUATION PLANNING}

After establishing the characteristics of the gold plating needed for switch tubes, the next phase of the evaluation was to reproduce this gold film using the sulfite plating baths. This evaluation represented the majority of work in this study. A detailed plan was prepared to accomplish this in the one-year time frame allowed for the ECM funded work. The summary of this planning is presented in Figure 7. 


\section{REVIEW VENDOR PLATING}

REPLICATE VENDOR

PLATING AT SNL/NM

ESTABLISH GOLD PLATING

CHARACTERISTICS

SET UP SULFITE BATH(S)

Au Plating evaluation

\section{ESTABLISH BATH LIMITS and CONTROLS}

Figure 7. Planning for Sulfite Gold Plating Evaluation

\section{INITIAL SULFITE GOLD PLATING EVALUATION}

Sulfite gold plating baths used in the initial plating evaluation were Technic TG25 and TG25E. The TG25 bath is a high pH gold sulfite chemistry while the TG25E bath is a somewhat neutral pH gold sulfite chemistry. Table 3 shows a comparison of the two sulfite gold baths. The readyto-use TG25 chemistry uses metallic brighteners while the TG25E chemistry requires an organic brightener.

\begin{tabular}{|l|c|c|}
\hline Bath Property & TG25 & TG25E \\
\hline \hline $\mathrm{pH}$ & $9.0-10$ & $6.0-7.0$ \\
\hline Temperature & $100^{\circ}-150^{\circ} \mathrm{F}\left(120^{\circ} \mathrm{F} \mathrm{Opt.)}\right.$ & $110^{\circ}-160^{\circ} \mathrm{F}\left(140^{\circ} \mathrm{F}\right.$ Opt.) \\
\hline $\begin{array}{l}\text { Current } \\
\text { Density }\end{array}$ & 1 - 4 ASF Rack, 1 - 4 ASF Barrel & 1 - 8 ASF Rack, 1 - 4 ASF Barrel \\
\hline
\end{tabular}

Table 3. TG25 and TG25E Sulfite Gold Plating Bath Comparisons

Plating Parameters and Setup

Both the TG25 and TG25E gold plating solutions used in the initial study were premixed at Technic, Inc. The baths were mixed to a gold density of 1 troy oz. per gallon 
of solution. It was further requested that no brighteners or additives be mixed into either bath because of our requirement that the gold coatings plated be soft, high purity gold. The sulfite plating baths were contained and used in one-gallon battery jars. Fixturing for gold plating consisted of two, $4 \times 8$ inches, platinumized titanium anodes immersed in the plating solution on each side of the tank. A hot plate with magnetic spinner capability was used to heat the plating solution and a small DC power supply furnished the plating current. Test samples were suspended in the plating bath using metal clips which also served as the cathode connection to the plating sample. Before heating and plating, a pH and Specific Gravity measurement were taken for reference.

The $2 \times 2$ inch test samples (described in Figure 3) were used in these initial, sulfite plating tests. The samples were processed through cleaning, nickel strike, electroless nickel plating, and then gold strike before final plating in the sulfite gold bath (as shown in Figure 2). The processing prior to final gold plating in the sulfite gold bath was identical to that developed for switch tube plating applications at the vendors. This was intentional, since we did not want to introduce new variables into the plating evaluation other than the sulfite gold. The initial plating parameters used for sulfite gold plating were maintained within the limits specified by the vendor. Plating current was maintained at 3 amps per square foot (ASF) and bath temperature at $150^{\circ} \mathrm{F}$ for both TG25 and TG25E plating baths. While heating and plating in the sulfite gold baths, a magnetic spinner was used to promote solution circulation. To plate the required gold thickness of 1 mil ( 25 microns) minimum, the 3 ASF plating current was maintained for 170 minutes.

\section{Initial Gold Plating Results}

Prior to sulfite gold plating, a test sample was plated using cyanide gold plating to verify the quality of new test samples which had been prepared for this part of the evaluation. No problems were found in plating these samples; consequently, four test samples were processed through cleaning, nickel plating, gold strike, and then plated in each of the sulfite plating baths. After plating, samples were visually inspected and then cut into smaller pieces to allow preparation of metallurgical samples. The metallurgical samples were inspected and analyzed for gold properties of the different coatings; the sample plated using cyanide gold was also prepared for gold analysis.

Visual inspection of sulfite gold coatings showed them to be generally uniform and of good color. The coating produced in the TG25 bath had a more bright and shiny luster than that produced by the TG25E gold bath. The TG25E bath coating had more of a matte finish with a gold color which was less yellow and had more of the visual characteristics of the cyanide gold color and finish. Some voiding was noted in the TG25 coating especially in the brazed areas and nodules were noted in all coatings regardless of bath type. Gold slivers as a result of plating were only noted in the TG25E coating. These observations and the measured gold properties are outlined in Table 4.

Differences measured in the gold plating characteristics of the three bath types are recorded in Table 4. The major difference in the two sulfite coatings is that the TG25 was harder than the TG25E coating. The Knoop hardness fell outside the limits of Type A soft coatings, being an average of 108.7. The TG25E coating Knoop hardness 
measured an average of 59.1 and was closer to the cyanide gold Knoop hardness of 47. Grain size of both sulfite coatings fell between 15 and 16 as compared to the grain size of 14 measured on the cyanide coating. All three gold coatings had thicknesses exceeding the 1 mil minimum required with all having at least one measurement falling below this requirement. The gold tended to be thicker on the moly coating than on the kovar section of

\begin{tabular}{|c|c|c|c|}
\hline Gold Property & $\begin{array}{c}\text { TG25 Sulfite Gold } \\
\text { Ave (Max/Min) }\end{array}$ & $\begin{array}{c}\text { TG25E Sulfite Gold } \\
\text { Ave (Max/Min) }\end{array}$ & $\begin{array}{c}\text { Cyanide Gold } \\
\text { Average }\end{array}$ \\
\hline \hline Au Thickness on Moly & $1.53(1.88 / 0.87)$ & $1.31(1.68 / 0.87)$ & 1.42 \\
\hline Au Thickness on Kovar & $1.45(1.62 / 1.09)$ & $1.23(1.47 / 0.99)$ & 1.28 \\
\hline Grain Size & $15.5(16.5 / 14.9)$ & $15.58(15.9 / 15.3)$ & 14.0 \\
\hline Hardness & $108.7(119.0 / 98.7)$ & $59.1(66.5 / 50.5)$ & 47 \\
\hline Color & Bright / Shiny & Good Yellow Matte & Good Yellow Matte \\
\hline Uniform & Yes & Yes & Yes \\
\hline Voids & Some & No & No \\
\hline Nodules & Yes & Few & Yes \\
\hline Slivers & Few & No & No \\
\hline
\end{tabular}

Table 4. Gold Properties of Sulfite and Cyanide Plated Coatings

the test sample. This non-uniformity is more likely due to the location of the kovar (in the center of the substrate) than any other plating characteristic. No adhesion tests were conducted on any of the coatings as this property was not of interest at this point in the evaluation.

\section{Sulfite Plating Bath Selection}

The TG25E sulfite plating bath was chosen as the prime candidate for replacement of the cyanide plating bath for switch tubes primarily due to the advantages of the neutral $\mathrm{pH}$ and the pure gold deposits. Because cyanide replacement is a major concern in all aspects of gold plating at SNL, it is most important that all other gold plating capabilities be assessed for possible elimination of cyanide. Also, the neutral pH of the TG25E gold bath is very attractive for use in hybrid microcircuit and printed wiring board substrates where organic mask and/or resists are employed.

The TG25 sulfite plating bath was not discarded as a candidate for replacing the cyanide gold plating chemistry. However, since conducting multiple tests on two sulfite baths would take twice the time and use up study resources, the TG25 bath was set aside to allow us to concentrate on the more promising candidate.

\section{GOLD PLATING PROBLEMS}

Initial testing on the sulfite gold coatings was successful in that proper gold thickness was obtained, gold hardness and grain size were comparable to cyanide gold, and uniformity was at least as good as the cyanide gold coatings over the plated surface. The data at this point showed the major difference in the coatings produced by the two candidate sulfite baths was the hardness of the gold and the luster or surface appearance. The concerns which resulted from the early evaluations was the voiding and nodules which occurred in and on the plated gold coating. Before proceeding with 
further characterization of the sulfite baths, it was decided to determine the origin of these problems.

\section{Voids}

The nodule problem which occurred in all sulfite gold plated coatings thus far was secondary to the voiding which was detected. The voiding represented a potential, catastrophic failure in the switch tube by allowing gases to permeate into the switch tube cavity. The voids were somewhat sporadic on the coated surface and were detected primarily in the braze area which was where the kovar and moly coated substrate were joined in the test samples. Few, if any, voids were detected in the smooth, regular surfaces on the remainder of the test sample. Consequently, the sections which were prepared to show the gold coating at this junction were polished and inspected using an iterative process to determine the origin of the problem. The metallurgical samples which exposed this joint in cross section were ground down to penetrate deeper into the joint area, polished to make the braze joint visible, then optically inspected to determine the source and/or reason for voiding. It became clear, after repeating this process on several metallurgical samples of braze areas, that the reason for the voids was the braze material. Large and deep voids in the brazed material were excessive and represented an area which could not be coated reliably. A section of one of these braze voids is shown in Figure 8. This particular joint was plated using the cyanide gold bath although similar voids were found in the braze area plated with sulfite gold baths. As seen in this photomicrograph, the voiding is wide and deep and presents a surface defect which is virtually impossible to plate. The analysis of the metallurgical samples also showed that in braze areas where the surface was void-free, if somewhat irregular, both cyanide and sulfite plated coatings were uniform and of sufficient thickness to provide a void free surface. Further, no voiding was detected in the metallurgical samples outside the brazed area. The conclusion from this analysis was that the brazing used to produce the test samples was defective and contained multiple voids which could not be gold plated reliably regardless of the plating bath used. At this point, it was decided to use brass or nickel sheets as the test samples for the balance of the studies on sulfite plating characteristics. The tests for coating non-uniform and brazed surfaces would be postponed until the end of the evaluation and conducted on actual switch tubes samples. 


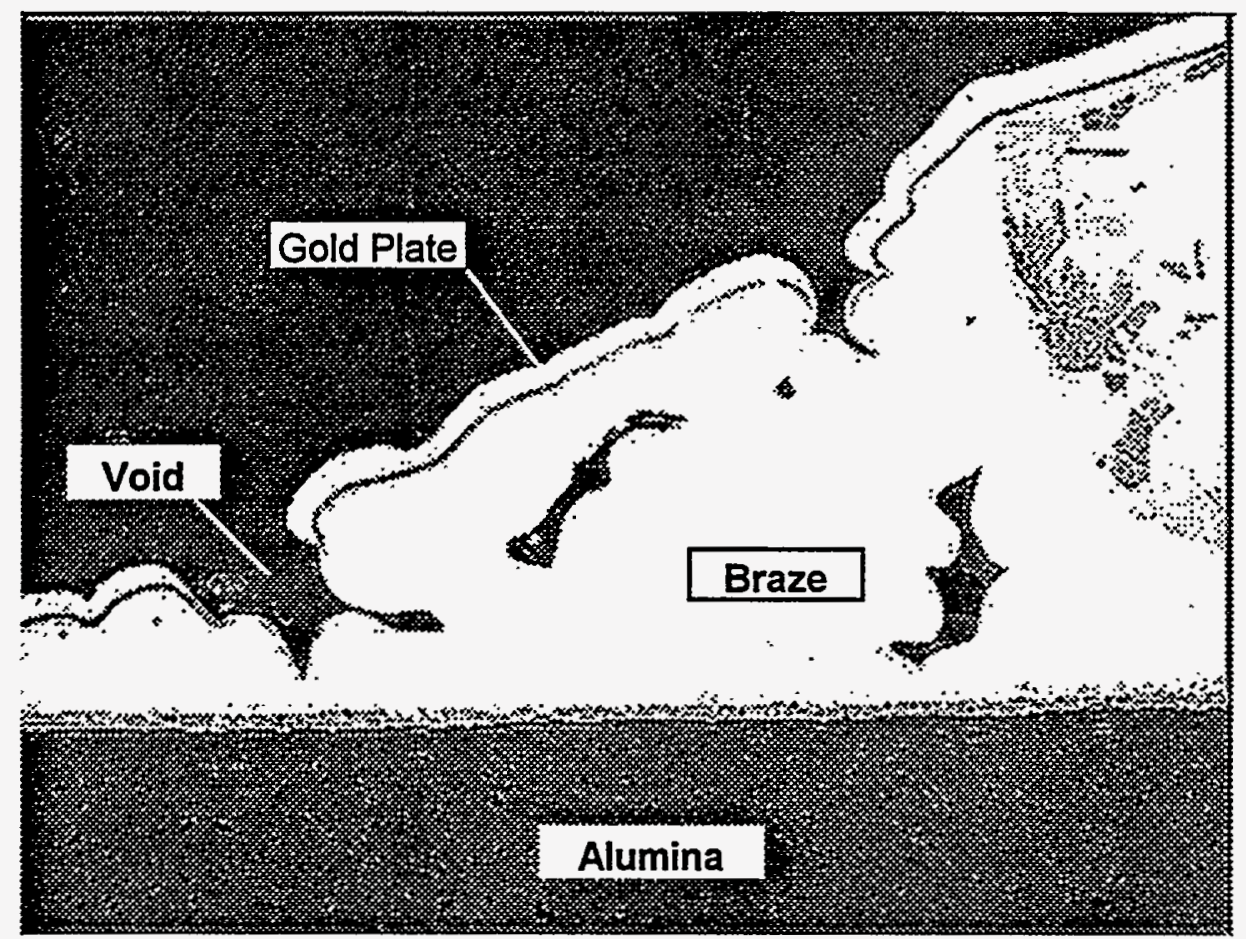

Figure 8. Metallurgical Cross Section Showing Voids in a Brazed Joint on Test Sample Number 10. The Test Sample Was Gold Plated in a Cyanide Gold Plating Bath

\section{Material Compatibility}

Another problem which occurred in early experiments was an incompatibility of the sulfite plating chemistry with brass. Brass panels are used in Hull Cell tests to determine the range of current density which produces good plating characteristics. After using brass panels in several Hull Cell tests, it was discovered that sulfite plating solutions became cloudy and filled with particles; this did not occur with the cyanide plating solutions. The clouding and particle effect happened regularly with the sulfite gold plating solutions regardless of Hull Cell test results. After performing several Hull Cell tests with brass panels, it was concluded that the brass and the sulfite bath chemistry were incompatible. This chemical effect was not explored, but the particles and clouding were eliminated by changing to nickel panels for Hull Cell tests.

\section{Nodules and Slivers}

A significant but not catastrophic problem which occurred on coatings plated with both TG25 and TG25E plating baths was that of gold nodules and slivers on the surface. These defects on the plated surface were more of a nuisance than a problem which would result in faulty coatings. They showed up on all the gold coatings which were plated to a thickness of 25 microns or more in both sulfite plating baths and were minimal in gold coatings which were less than 10 microns. The nodules ranged from 1 to 5 mils in diameter in quantities which ranged from a few to excessive over the plated sample. Slivers which occurred with somewhat less frequency were from 5 to 25 mils in length and about 1 to 3 mils in diameter. There were two concerns associated with the 
nodules and slivers: 1) they were aesthetically unsightly and, if excessive, produced a fuzzy, non-uniform appearance in the gold plated surface, and 2) the origin and cause of these projections might affect the chemistry of the bath and the bath life over the long term.

The first tests to determine the origin of the nodules were conducted using a different test sample in both suffite plating baths. Our experience with the brass used in Hull Cell testing showed that the sulfite plating chemistry was incompatible with brass. The hypothesis adopted for these tests was that maybe some of the materials used in the original test samples (kovar, moly manganese, braze material, etc.) was reacting with the sulfite bath and producing the nodules. It was known that the preferred plating surface for sulfite gold baths was nickel, so nickel panels were cut to $2 \times 2$ inch sizes for plating tests. Cursory tests were conducted on the nickel panels by plating in both TG25 and TG25E plating baths. The nickel panels were cleaned and nickel strike plated (to minimize any contaminants on the test panel) and then gold plated to a coating thickness of 1 mil. Current density was maintained at 3 ASF for plating tests in both sulfite baths. The results were negative as both baths produced gold nodules on the plated surfaces. Gold nodules were occurring on both sides of the plated samples on coatings produced in both plating baths. A few but minimal quantities of gold slivers were also appearing on the plated surfaces. To gain more insight into the nodule formation, the gold plated nickel test samples were cut up and then mounted into metallurgical samples for cross-sectional review. Visual inspection of the metallurgical cross sections of the sulfite gold coatings showed the nodules to be a surface phenomena. A photomicrograph of one of the nodules is shown in Figure 9. The nodules are attached to the gold surface and do not extend downward toward the surface being plated. This led to the conclusion that the nodules were formed or attaching themselves to the surface of the gold coating at some time during the plating operation and are not generated in the gold plated film. A second observation was that, during the plating operation, particles formed in the plating bath(s) and were made visible by shining a light through the plating bath solution. This occurred even though the solution was clear with no particles visible prior to plating. 


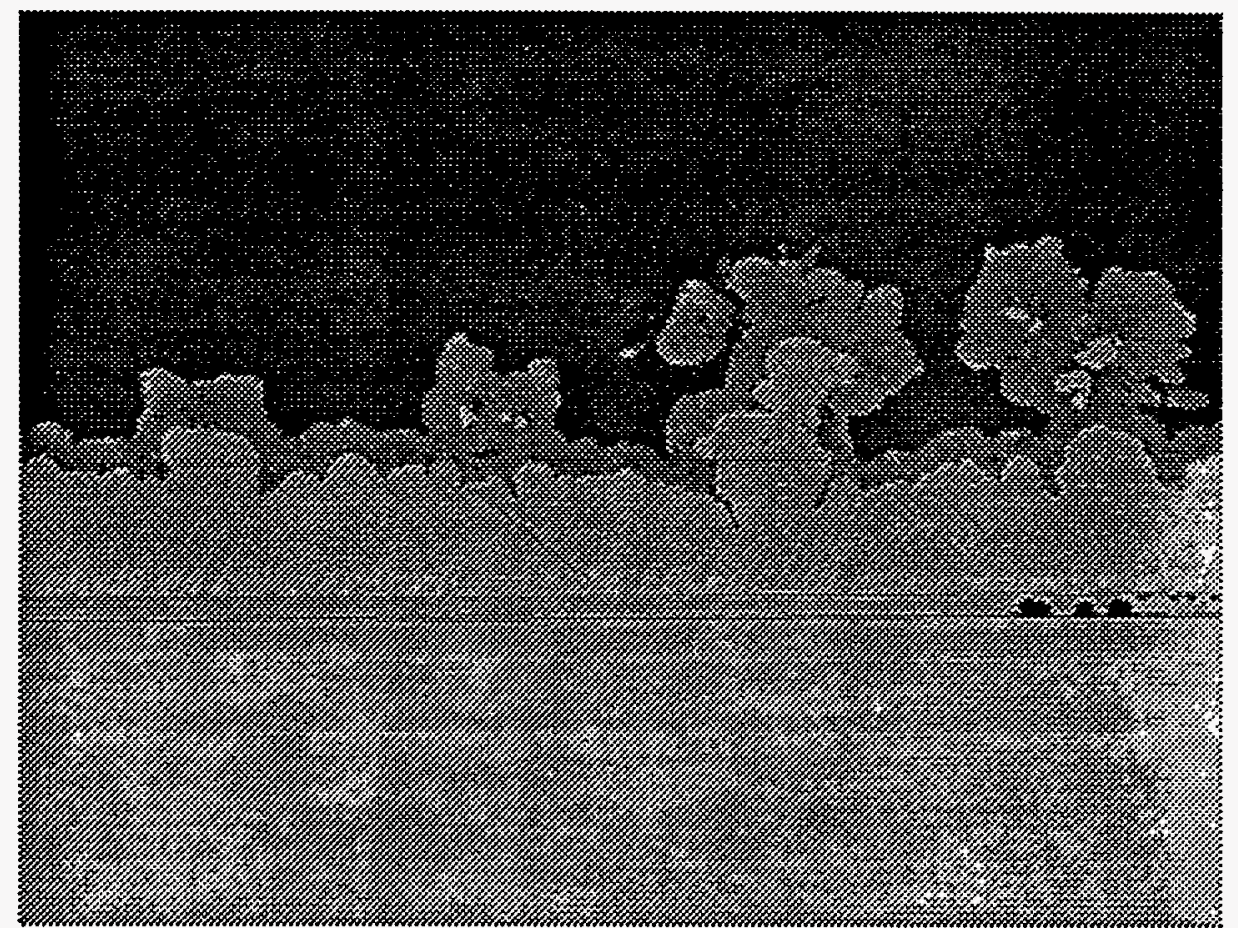

Figure 9. Photomicrograph of Nodules Produced by Sulfite Gold Plating Bath TG25E

\section{TG25E Sulfite Bath Filtering Experiment}

The particles found suspended in the sulfite plating bath after plating were suspected of contributing to the nodule problem. Consequently, a test was planned to determine if removing these particles would resolve the nodule problem. In addition, a secondary test was planned to determine if the electroless nickel plating bath was contributing to the nodule formation. The test plan was as follows:

- Filter the TG25E sulfite plating bath which was in use.

- Perform a Hull Cell test on the TG25E bath after filtering.

- Plate four test samples using the switch tube plating process.

- Pull two samples prior to electroless nickel plating and proceed to gold strike (skip electroless nickel plate).

- Gold strike all four test samples to obtain a seed layer of electroplated gold.

- Pull two samples after gold strike for visual inspection (for nodule formation).

- Electroplate two test samples to 1 mil gold thickness in the TG25E filtered bath--one with electroless nickel plating and one without this plating. 
The TG25E sulfite gold bath was pre-filtered using number 42 filter paper to remove particulates. It required three filter changes before the bath was completely filtered; the filter clogged with particles before complete filtration. The bath was then charcoal filtered to remove any organics which might be contributing to the particle formation and/or nodule problem. The plating tank was cleaned prior to refilling with the filtered plating solution. Visual inspection of the TG25E plating bath after filtering showed it to be free of any particulates and clear with a slight yellow tinge. A Hull Cell test was performed on the filtered bath at this point to check plating characteristics. This test indicated good gold plating characteristics for a current density range of 0 to 6 ASF and no nodule formation on the Hull Cell plated sample. Plating tests outlined above were then performed using the filtered TG25E gold bath.

The test results showed that nodules formed on all the test samples regardless of preplate conditions. The test samples plated with electroless nickel had gold nodule formation on the surface the same as those without the electroless nickel plating. Figure 10 is a photomicrograph of a typical area of one of the test samples showing gold nodules on the plated surface. There was no indication of nodule formation on the test samples which had only been plated with the gold strike. Visual inspection of the sulfite plating solution showed that particles had again formed in the plating bath.

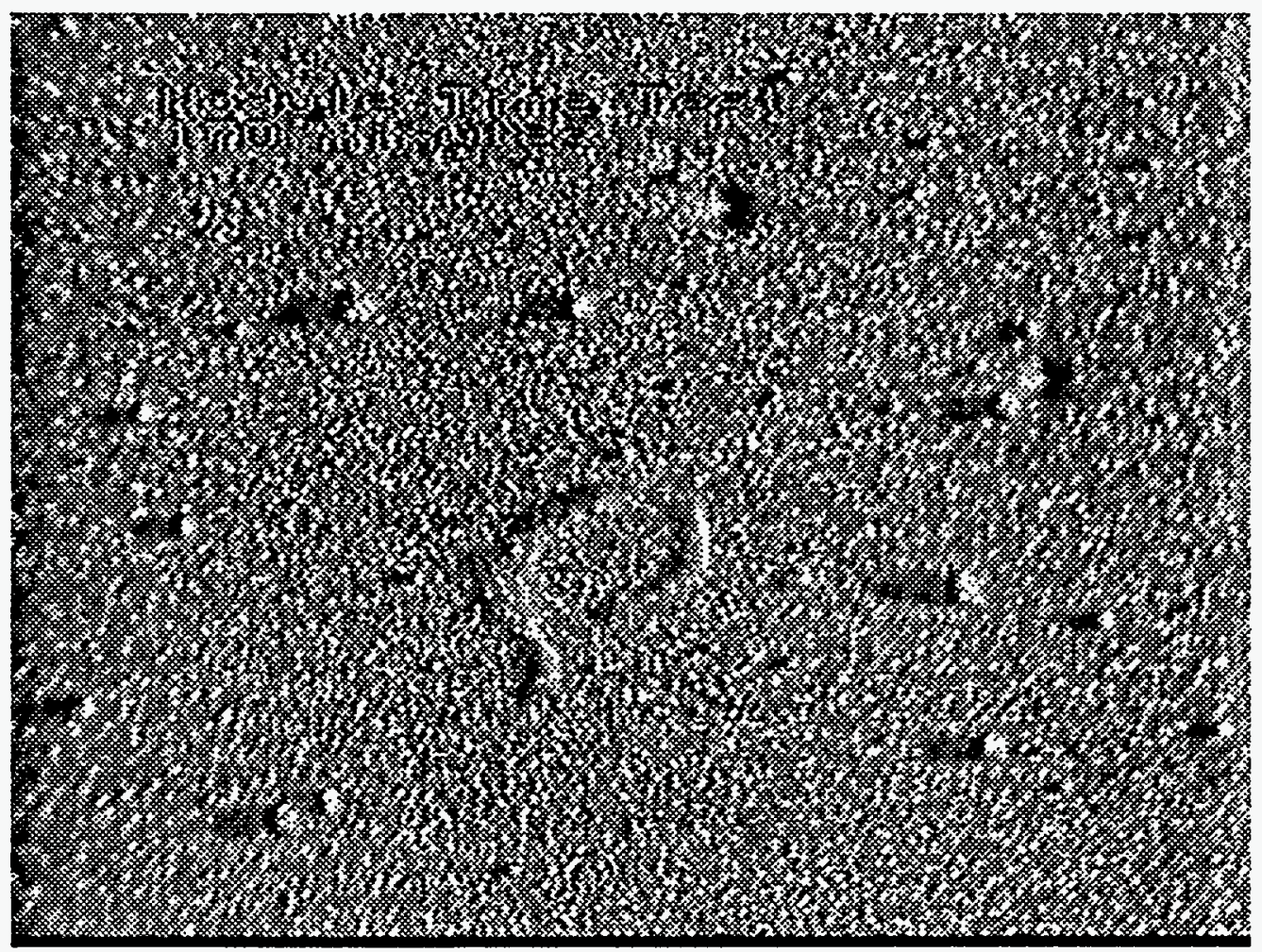

Figure 10. Photomicrograph of Gold Nodules on Plated Surface of Test Sample. Gold Plated Using TG25E (Filtered) Gold Bath.

These results lead to the early conclusion that the nodule formation was occurring because of the sulfite gold plating solution. Filtering out any particles which formed in the bath did not solve the nodule problem, and the particles reappeared after continued plating. Also, based on these cursory tests, the plating processes prior to sulfite gold 
plating did not seem to contribute to the problem. Another clue to the nodule problem was that the TG25E gold plating bath had been characterized in prior years for pattern plating gold conductors on hybrid circuits. There was no evidence of nodule formation on these circuits. For conductor plating, the gold was limited to a thickness of 3 to 6 microns instead of the 25 microns and above that were required for switch tube applications. It was speculated that the extended plating time (170 minutes) was contributing to the problem; consequently, another test plan was devised to evaluate this theory.

\section{STEP TEST EVALUATION}

A diagonostic test was developed for the sulfite plating bath study which was designated "Step Testing." This test procedure was developed after extended analysis on the sulfite gold coatings and many discussions on the reasons for the nodule formation. The primary purpose of the test was to determine if and when the nodule formation was occurring during sulfite gold plating. Test results had indicated the nodules were forming during the extended plating time in the sulfite plating solution; consequently, this test would provide insight on the time of nodule formation. The test and the results thereof were instrumental in providing the reason and cure for nodule formation. Test description and results are outlined in this section.

\section{Step Test Procedure}

The step test was developed to allow inspection and testing of plating bath coatings without sacrificing large quantities of gold. The test was developed to see at what point in the plating process the nodule formation was happening. The Step Test generally has the effect of pulling a part out of the plating bath at intervals in the plating process. The advantage is that it requires only one plated sample in the bath. The test is performed as follows:

- Cut a brass Hull Cell panel into a 2-inch-wide strip along the length to make a Step Test plating panel.

- Mark off 0.5 inch lengths along the test panel with deep scribe marks.

- Electroplate the test panel with Nickel.

- Calculate the plating current to provide the ASF desired on the total panel (both sides) and that for a $0.5 \times 2$ inch area (both sides).

- Immerse the panel completely in the plating bath and plate at the total current calculated.

- At some desired time interval during plating, pull the panel up in the plating solution to the next 0.5 inch scribe mark and reduce plating current to compensate for the decreased plating area.

- Continue plating until the next desired time interval and repeat the previous step. 
- The test (or time intervals) should be preplanned such that the last segment on the Step Test panel receives the total plating time of the process under investigation.

The Step Test panel after plating with this procedure has gold coatings which increase in thickness along the length of the panel. These steps represent different plating times in the gold plating process. It is then possible to inspect and analyze these different step platings to determine what has happened during the plating process. A Step Test panel after plating is shown in Figure 11.

\section{Test for Nodules Using The Step Test.}

The Step Test was performed on the same TG25E plating bath which was used in our prior studies. Data logs on this plating bath indicated it was still within vendor-specified operating parameters. The sulfite gold plating bath was filtered using number 42 filter paper prior to testing. This removed visible particles suspended in the plating solution which might contribute to the problem. Step Test current density was calculated for the 3 ASF density used in all prior testing and recommended by the vendor. The test was performed with steps being plated at 60 minutes and 30 minute segments thereafter up to the 170 minute plating duration.

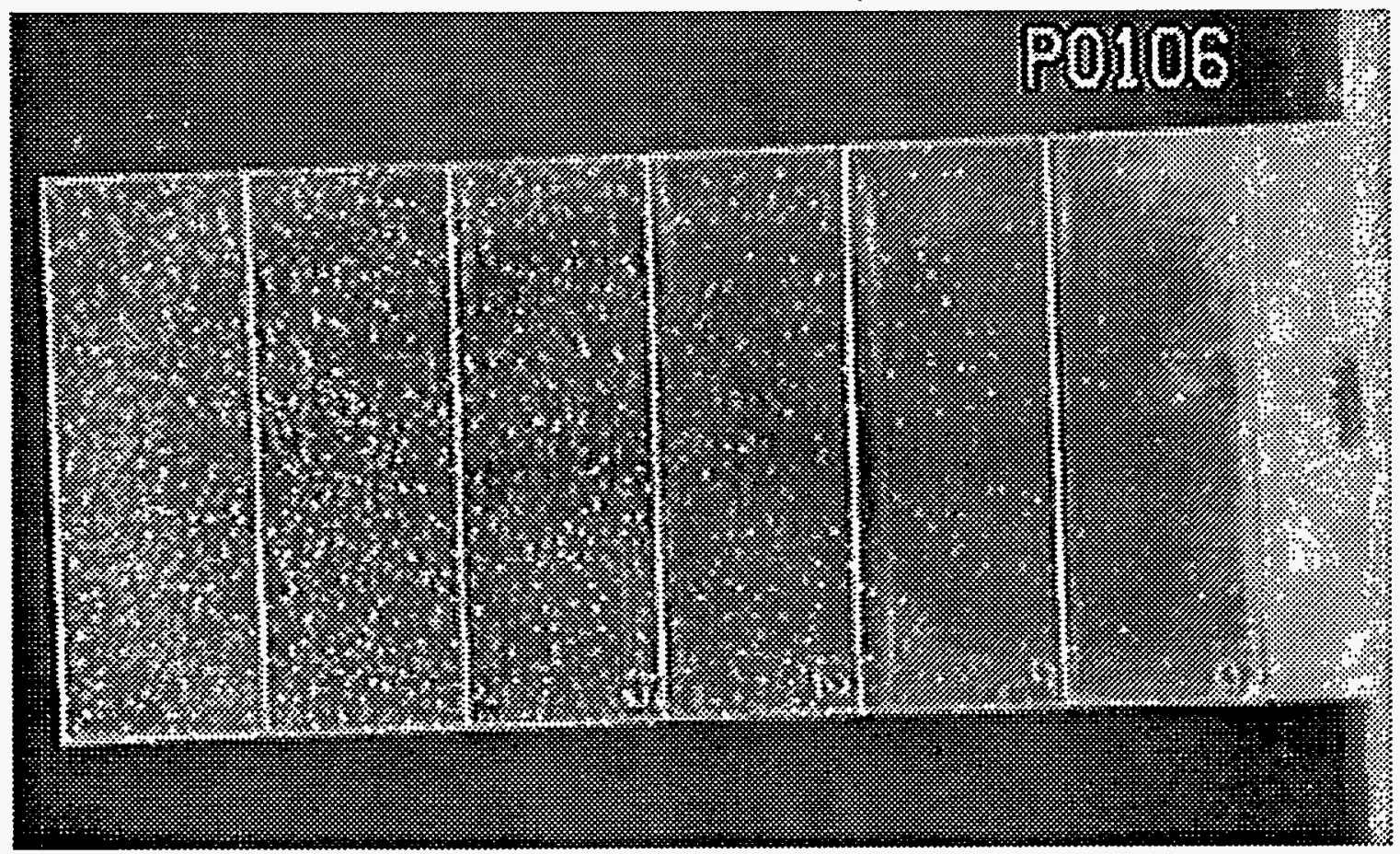

Figure 11. Step Test Panel After Plating Using the Step Test Procedure

Results of this test provided the first hard evidence that the nodules were forming as a result of extended plating time in the sulfite plating bath. Visual inspection of the test panel showed the gold nodules were formed in increasing size and quantity as plating time increased. Nodules started forming within 60 minutes and increased in size and quantity in each $\mathbf{3 0}$ minute step segment. A sliver was also present on the final step segment which verified the slivers were formed during plating. Enlarged photos of the 
gold coatings on different segments are given in Figure 12 which shows the quantity and size of nodule formation.

A visual inspection at high magnification was used to quantify the results of this test. Nodule size and quantity were measured and counted on each of the steps (representing increased time of gold plating). This provided a quantitative record of the phenomena. These results are shown graphically in Figure 13.

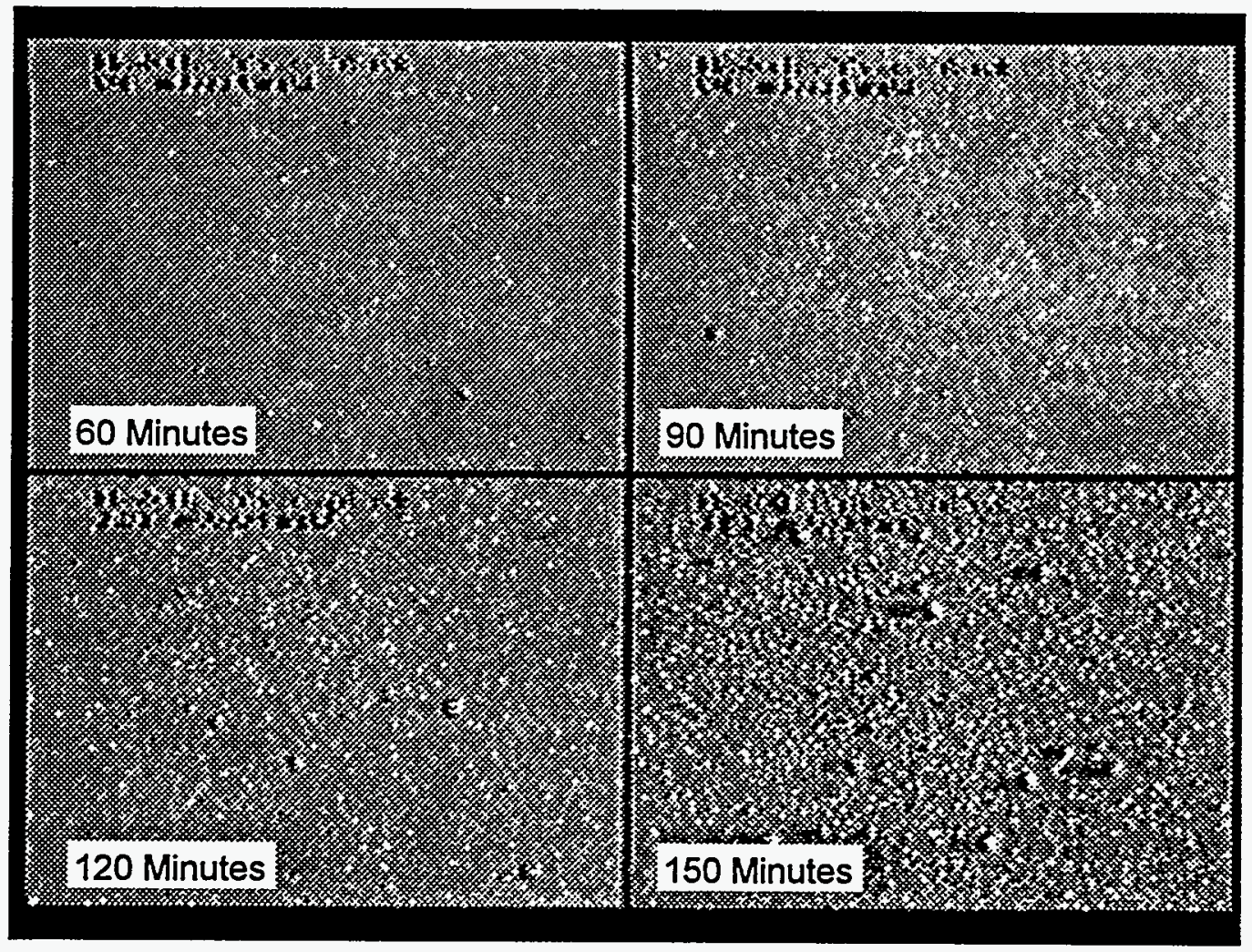

Figure 12. Photos of Gold Coatings on a Step Panel Which Show the Formation of Nodules During Plating in a TG25E Sulfite Gold Plating Bath 


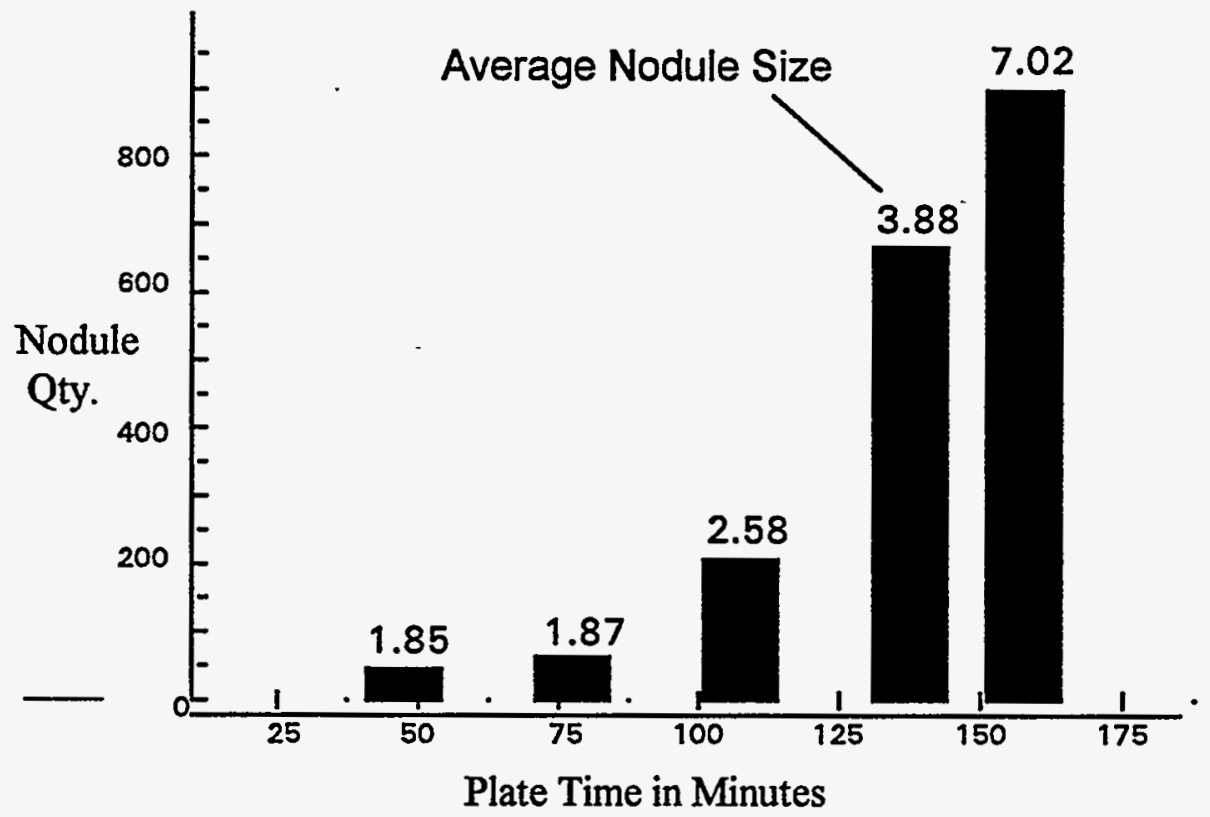

Figure 13. Graph of Nodule Quantities and Sizes Which are Formed During Sulfite Gold Plating

\section{NODULE FORMATION}

With the Step Test evidence that nodule formation was occurring in the sulfite gold plating bath, it was now imperative to find the cause and/or the cure for this problem. To check for cause of the nodule formation, analysis was performed on the residue which was collected in the filter used prior to plating. A sample piece of the filter which contained visible particles was analyzed using SEM/EDS analysis. A SEM photo of the filter section analyzed is shown in Figure 14. No foreign metallic species nor organic material were found on the surface of the precipitated gold nor further into the core of the material. 


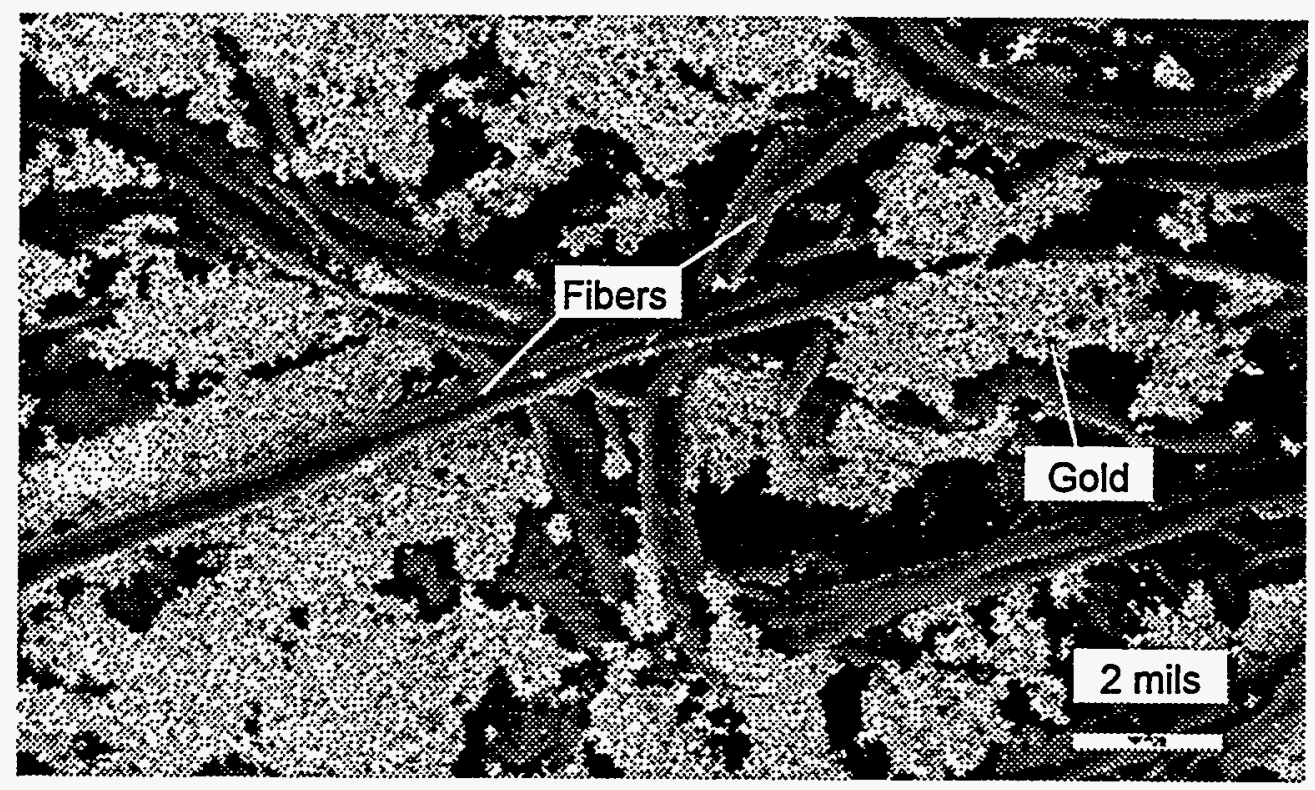

Figure 14. SEM Photo of Particles Trapped in Filter Paper Used to Filter Sulfite Gold Plating Bath

The SEM/EDS analysis did not provide information on how the nodules were formed during plating (Figure 15), however, it did provide data that no extraneous elements were present in the gold particles found filtered out of the sulfite gold bath. A possible explanation for nodule formation during gold plating is that due to the $\mathrm{pH}$ being at 6.0 to $7.0, \mathrm{SO}_{2}$ is being generated continually; consequently, if the sulphite is allowed to fall appreciably below 4.0 ounces per gallon, gold will precipitate out of solution. It is this precipated gold particulate that attaches to the surface being plated and initiates the nodule formation as gold is deposited around it. It is important to analyze for the complexing agent (sulfite) and to maintain it to 6.0 ounces per gallon to alleviate the gold precipitation problem. Also, real time filtering of the bath should remove any of this gold particulate. This technique was attempted as a further cure for the nodule problem. 


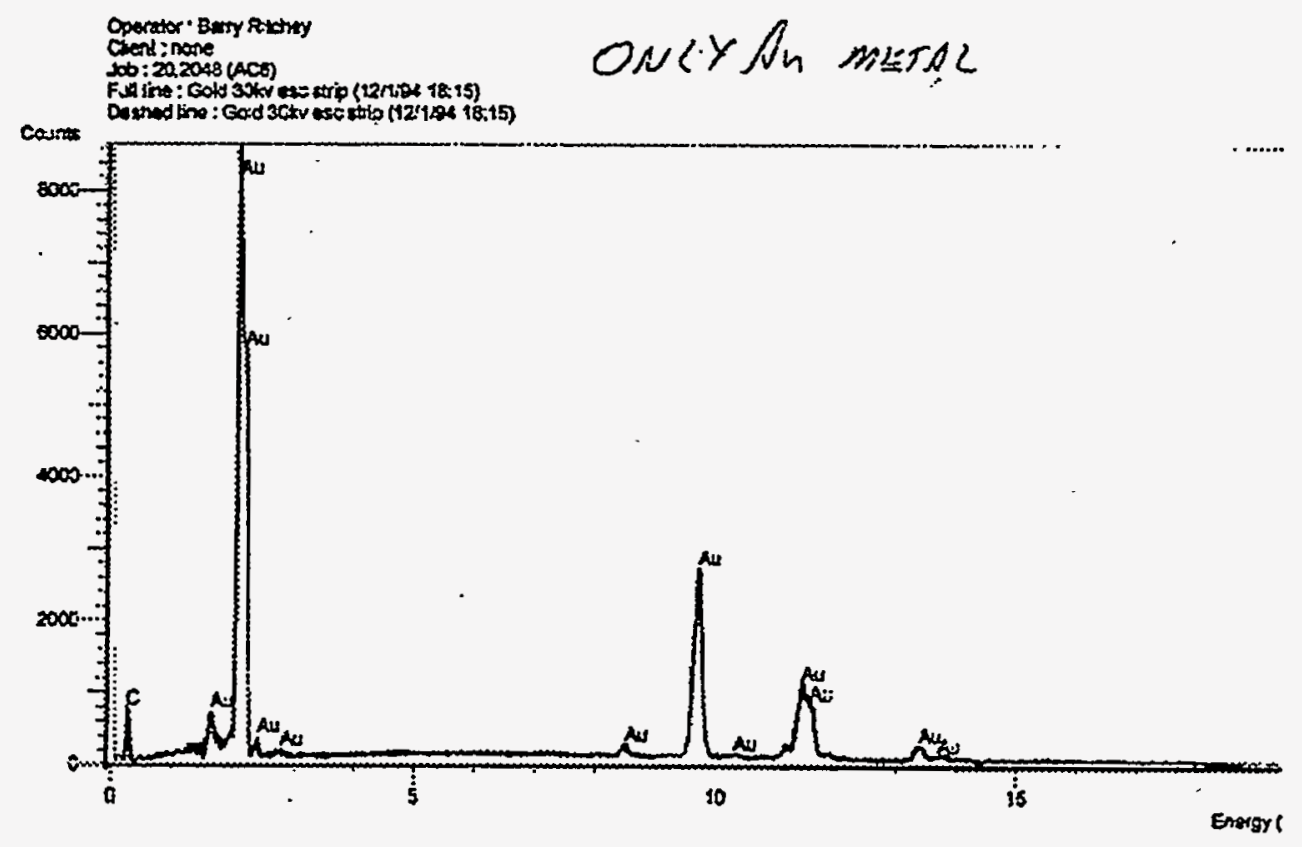

Figure 15. Element Analysis ofParticles Suspended in Sulfite Gold Plating Bath

\section{Filtering During Gold Plating}

In commercial or high volume plating, a filtration system is customarily included in the plating tank apparatus. Active filtration provides insurance that unwanted particles which are formed or introduced in the plating bath are removed. These could affect bath life and the quality of plated films. Also, the pumping of the solution acts to increase the agitation in the bath and flow of plating solution past the plated part which has beneficial effects. Filtering had not been incorporated into our setup because of the small size of the bath and the fact that evaluations were conducted in a clean room. Therefore, it was necessary to find a filtration system which could be brought into a clean room and provide filtering of the small plating bath during operation. A small peristaltic pumping system was located with a filtration bowl that suited our needs. Fiber filter pads were purchased for the filtration bowl which provided filtering of the bath to a 3 micron particle size. Tooling and plumbing were constructed to siphon plating solution from the bath, pipe it to the pump and filter, and then direct it to the bottom of the plating tank. A diagram of this system is shown in Figure 16.

For initial testing of the effects of active filtration on sulfite gold plated coatings, a new plating bath was used. This TG25E sulfite solution with an increased gold content of 1.5 Troy Oz. per Gallon was obtained from Technics (prior plating solutions contained a gold content of 1.0 Troy Oz. per Gallon). The higher gold concentration was used for two reasons: 1) Talks with the vendor had indicated a higher gold content was needed for our application, and 2) A higher gold content would produce a worst-case scenario for gold precipatate and subsequent nodule formation. Nickel test panels were cut to a $3 \times 3$ inch size for first-attempt plating using the new filtration system. Panels were cleaned and then electroplated with a gold strike prior to sulfite gold plating. The filtration pump was turned on during bath heat-up, and filtering of the sulfite gold plating bath was maintained until plating was complete. 


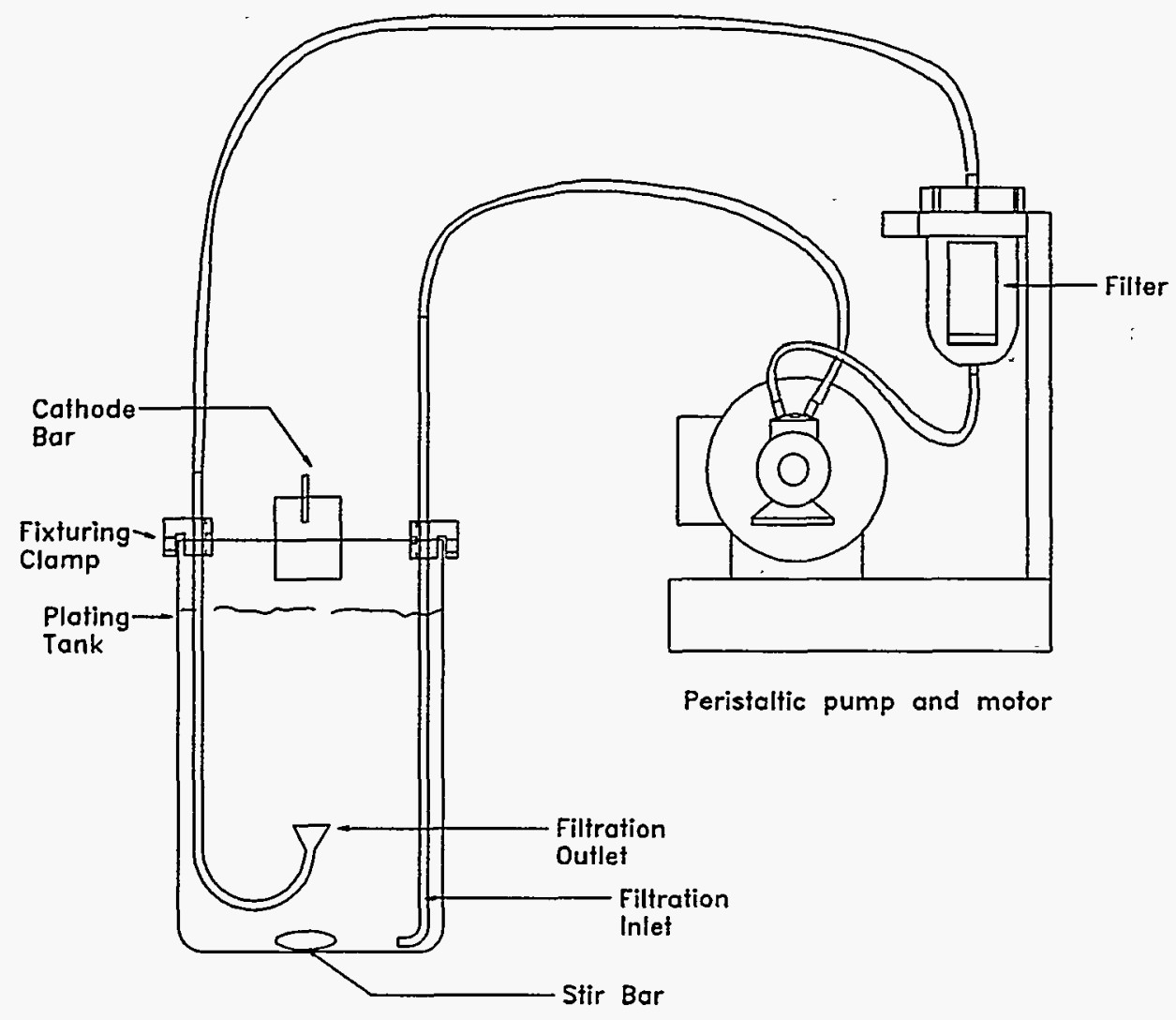

Figure 16. Diagram of Active Filtration System Used for Sulfite Gold Plating Bath

The first panel which was gold plated using the active filtration setup was not a complete success. The gold coating was foxy brown and results were nebulous on whether a nodule-free gold coating was obtained. A second panel, which was plated identically to the first, produced more positive results. The coating had a good, gold color on both sides with a matte finish. The coating surface was free of nodules and slivers. This result continued with further gold plating in the sulfite plating bath and confirmed our suspicions about the reason for nodule formation. The poor, initial gold coating produced in the new plating bath was attributed to a general characteristic of some plating baths; that is, some baths require a break-in period of electroplating before good plated coatings are obtained. With the positive filtration results thus established, the filter system was used and maintained as an intergral part of the plating process for sulfite gold plating in all subsequent evaluation testing. The filter would turn from dark brown to gray with particle accumulation after two to three platings of 170 minutes indicating that gold continued to precipitate during the life of the sulfite plating bath. 


\section{SULFITE GOLD PLATED COATINGS}

The evaluation up to this point had taken an unplanned course of resolving problems caused by test samples, voiding, nodules, and slivers. As a result, time for performing the intended evaluations on the plating characteristics of the sulfite gold plating baths and the resultant coatings was limited because of funding and time constraints. However, much had been learned about plating with the new generation of gold sulfite plating baths while resolving these problems. It was intended to increase this knowledge of the sulfite plating system in the time remaining.

\section{Coating Thickness}

As a precursor to further plating evaluation, a thickness evaluation was conducted on the underplated coatings used in the switch tube plating process. This was done to ensure that the plating baths setup at SNL/NM were performing within acceptable limits. The test was performed using a sequence test in which several test samples were plated simultaneously with one sample being pulled from the sequence at each plating step. To ensure a good metallurgical thickness measurement, $1 \times 1$ inch brass panels were used as the test samples which provided a good, hard base for cross-sectioning. Also, each sample was copper plated after removal from the sequence to trap the plated coating on the topside. The standard cleaning and pre-gold plating processes used in switch tube plating (Figure 2) were accomplished and then thicknesses of each coating evaluated. The range of coating thicknesses measured on these samples is given in Table 5.

\begin{tabular}{|c|c|c|}
\hline Coating Thickness Measure & Vendor Plated Sample & SNL Plated Sample \\
\hline Nickel Strike & No data & $0.034-0.039$ mils \\
\hline Electroless Ni Plate & $0.82-1.103$ mils & $0.124-0.137$ mils \\
\hline Gold Strike & No data & $0.023-0.030$ mils \\
\hline Final Electroplated Gold & $0.80=1.65$ mils & $1.381-1.396$ mils \\
\hline
\end{tabular}

Table 5. Range of Film Thicknesses for Vendor vs. SNL Plated Coatings.

These thickness results indicated the SNL plating process produced a thinner electroless nickel than the vendor plating process. The final gold plating fell between the range of thickness measured on the vendor coating. No data was available on the thickness of nickel or gold strikes plated at the vendor facility; however, as intended, these coatings were very thin measuring less than 1 micron. The nickel strike approached 1 micron in thickness (0.94) and the gold strike was considerably less, having a thickness of about 0.7 microns. The major concern as a result of this analysis was that the SNL electroless nickel was almost a factor of 10 thinner than that of the vendor electroless nickel. This feature could be easily remedied by increasing the time in the electroless nickel plating bath.

\section{Current Density}

Technical data sheets from the Technics Inc. specified that sulfite gold plating baths should be operated at a current density between 1 and 5 ASF. Our early analysis using Hull Cell panels indicated that the TG25E sulfite bath plated good gold deposits 
in this range and perhaps a small amount higher. The advantage of plating at higher current densities is primarily shorter time in the plating bath to produce the same coating thickness. This is beneficial from a manufacturing standpoint for more throughput. The problem with plating at higher current densities is that this sometimes has a deleterious effect on the resultant coating and the plating bath. A test was performed to determine the effect on the gold coatings plated in the TG25E bath as a result of higher current density plating.

The current density test was conducted on small, $1 \times 1$ inch samples to avoid any problems with gold depletion during testing. Also, the test was performed early in plating bath life for the same reason. Current densities of 3 ASF and 6 ASF were evaluated in producing a gold coating thickness of 1 mil minimum. The plating bath used had a gold content of 1.0 troy oz. per gallon. Measurements taken before the test showed a pH of 6.80 and a specific gravity of 1.080 indicating the bath were well within specification limits. Testing was performed prior to the conclusion of filtering tests and were conducted without benefit of the active filtering installed later. The panels were processed with a nickel strike, an electroless nickel plate, and a gold strike before electroplating in the TG25E sulfite plating bath. The sample identified as $Y$ was plated in the sulfite gold bath for 170 minutes for a total of 7.14 Amp-minutes of electroplating. These plating parameters were the same as those used in switch tube cyanide gold plating. The higher current density sample identified as $X$ was also plated for 170 minutes for a total of 14.23 Amp-minutes. The plating time for sample $X$ was longer than planned because of a miscommuni-cation of the test procedure; it was intended that the plate time for the higher current density sample (6 ASF) be one-half that for the lower current density sample or 85 minutes. After plating, the samples were copper plated to entrap the gold deposit and permit more accurate metallurgical sample analysis (less smearing of metals during sample polishing). Properties of the two gold coatings are shown in Table 6.

\begin{tabular}{|l|c|c|}
\hline $\begin{array}{c}\text { Measurement on } \\
\text { Gold Coating }\end{array}$ & $\begin{array}{c}\text { 3 ASF Plating Current } \\
\text { Sample Y }\end{array}$ & $\begin{array}{c}6 \text { ASF Plating Current } \\
\text { Sample X }\end{array}$ \\
\hline \hline Ave. Gold Thickness (mils) & 1.38 & $1.28\left[{ }^{\star} 2.049\right]$ \\
\hline Grain Size (no units) & 14.9 & 14.3 \\
\hline Hardiness (Knoop) & 87.7 & 86.3 \\
\hline \multicolumn{2}{|c|}{ *Ave. Nodule Thickness }
\end{tabular}

\section{Table 6. Properties of Gold Coatings Plated at Moderate and High Current Density in TG25E Gold Sulfite Plating Bath}

Results of the current density study showed that the grain size and the hardness of the gold coatings were comparable. These were the two properties which were of most interest since they would be expected to indicate any major change in the gold coating by plating at a higher current density. Grain size of both coatings was in the 14 range and the Knoop hardness was within the A class of gold coatings, being about 88 and 86 respectively. The hardness measurements were taken on the metallurgical samples at coating thicknesses which were identical to provide better accuracy in the data (plating thickness will influence hardness measurements). The gold thickness data was not helpful in the analysis, because the increased plating time at higher current density on sample $X$ resulted in larger nodules and not increased average gold thickness. 
Nodule sizes averaging about 2 mils were measured on the surface of this sample. Average gold thickness on sample $Y$ was about as expected, being 1.38 mils. These results substantiated the conclusion that active filtering during plating was important in obtaining nodule free coatings. The results also gave a cursory indication that the TG25E gold bath would produce good gold coatings at current densities up to 6 ASF.

\section{SULFITE PLATING BATH LIFE}

Plating bath life is a vital characteristic to be evaluated when selecting any chemistry for plating applications. The plating bath must be capable of producing good quality coatings over extended periods of use time and be easily maintained. This was one of the shortcomings of the sulfite plating baths in the past. In our final evaluations, it was desired to obtain at least an indication of the TG25E sulfite plating bath life characteristics. To do this, a Depletion Test was devised.

\section{Depletion Test}

The objective of the Depletion Test was to reduce the gold in the bath over a period of time by plating several lots of parts in a manner similar to that which would be used in its intended application. Bath chemistry is monitored and samples of the bath removed for analysis after each plating run. The Depletion Test method in our study was conducted as follows:

1. Cut a $2 \times 2$ inch nickel panel for plating.

2. Clean the panel in a Shipley 1175 solution, rinse in DI water, and then dry with nitrogen.

3. Cathodically activate the nickel in a $50 \% \mathrm{HCl}$ acid solution.

4. Electroplate the panel with a nickel strike.

5. Electroplate the panel with a gold strike, rinse, and dry with nitrogen.

6. Weigh and record the mass of the panel in grams.

7. Electroplate a 1 mil minimum thickness of gold in the TG25E plating bath.

8. After plating, rinse and dry the panel and re-weigh; record the weight gain.

9. Remove a small sample of gold bath for analysis.

10. Perform a Baume (specific gravity) and pH test on the TG25E plating bath.

11. Inspect the plated gold coating for uniformity, color, and defects.

This procedure was repeated several times in the plating bath until such time that poor or insufficient gold coatings were obtained on the test panels. The $3 \times 3$ inch panel size was selected to minimize the number of tests to deplete the bath of gold since 
plating time was significant for the thickness of gold desired. Generally, it required an entire day of cleaning, preparation, and plating to perform one Depletion Test.

\section{Depletion Testing}

Evaluation tests on plating bath variables, bath chemistries, and their interrelationship become extensive and require significant time and experiments to get meaningful data. This evaluation was limited in its scope to determining whether a direct replacement of cyanide with sulfite gold plating was possible. Therefore, the time and expense required to fully evaluate all the variables and interrelationships was not feasible. The Depletion Test was formulated to obtain the maximum amount of information possible on plating bath life and to determine whether replacement of the cyanide gold chemistry was possible.

Depletion testing was conducted on two TG25E, sulfite, plating baths pre-made and purchased from Technic, Inc. The plating baths were labeled $C$ and $D$ for identification. Previous sulfite baths obtained for evaluation were ordered with a 1.0 troy ounce per gallon gold content. In talks with Technic, the gold content was discussed; and they recommended a higher gold content for our application of thicker gold coatings. This, combined with the desire to perform testing through a larger range of gold content, resulted in the $C$ and $D$ baths being ordered with a gold content of 1.5 troy ounces per gallon. Depletion testing was performed initially on the $C$ bath and followed by similar testing on the $\mathrm{D}$ bath.

Tests were conducted on the sulfite TG25E gold bath identified as $C$ bath prior to completion of the testing and resolution of the nodule problem. These tests confirmed our suspicions that the nodule formation was contributing to poor gold coatings and efficiency of the sulfite plating bath. During depletion testing, the $C$ bath was filtered on two occasions to remove particles which formed and were suspended in the plating solution. No adjustments were made to the bath during depletion tests except to replace water which evaporated during operation. Plating tests were conducted through a total of 345 Amp-Minutes at a current density of 3 ASF. Each panel required about 50 Amp-Minutes of plating to produce the 1 mil gold thickness. Weight gain of the panels did not correlate to the gain expected based on historical efficiency of gold deposited by electroplating: Typical efficiencies of gold plating baths are expected to be in excess of $95 \%$ with some decrease over the life of the plating bath. As seen in Figure 17 which shows a chart of the efficiency of sulfite gold plating bath $\mathrm{C}$ over several plating runs, only in run 2 did plating exceed $90 \%(91.3 \%)$. The other plating runs exhibited efficiencies less than $65 \%$. The low, gold plating efficiency did not appear to be related to the gold content of the bath as they were observed over the entire range of gold content in bath $\mathrm{C}$. The gold content which was measured from the samples taken after each plating run is shown in the chart of Figure 18 . The gold content measured 1.45 at the start and decreased steadily ending up at 0.172 troy ounces per gallon at the conclusion of testing. 


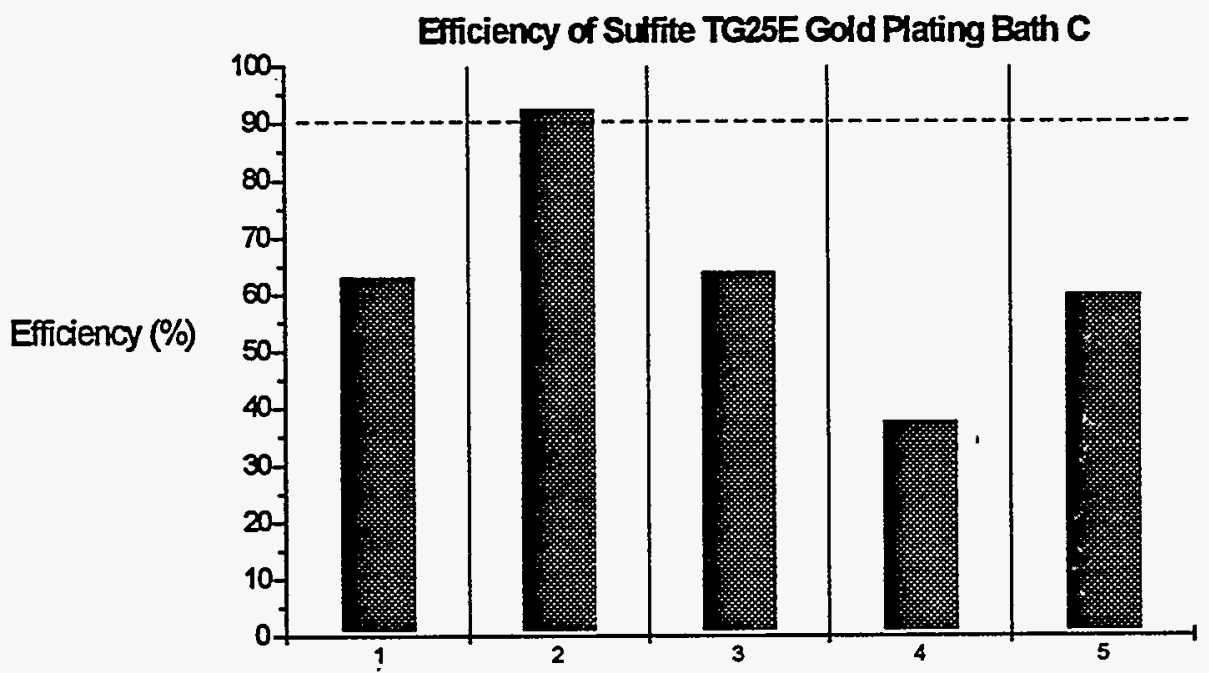

Figure 17. Electroplating Efficiency of Sulfite TG25E Gold Plating Bath C

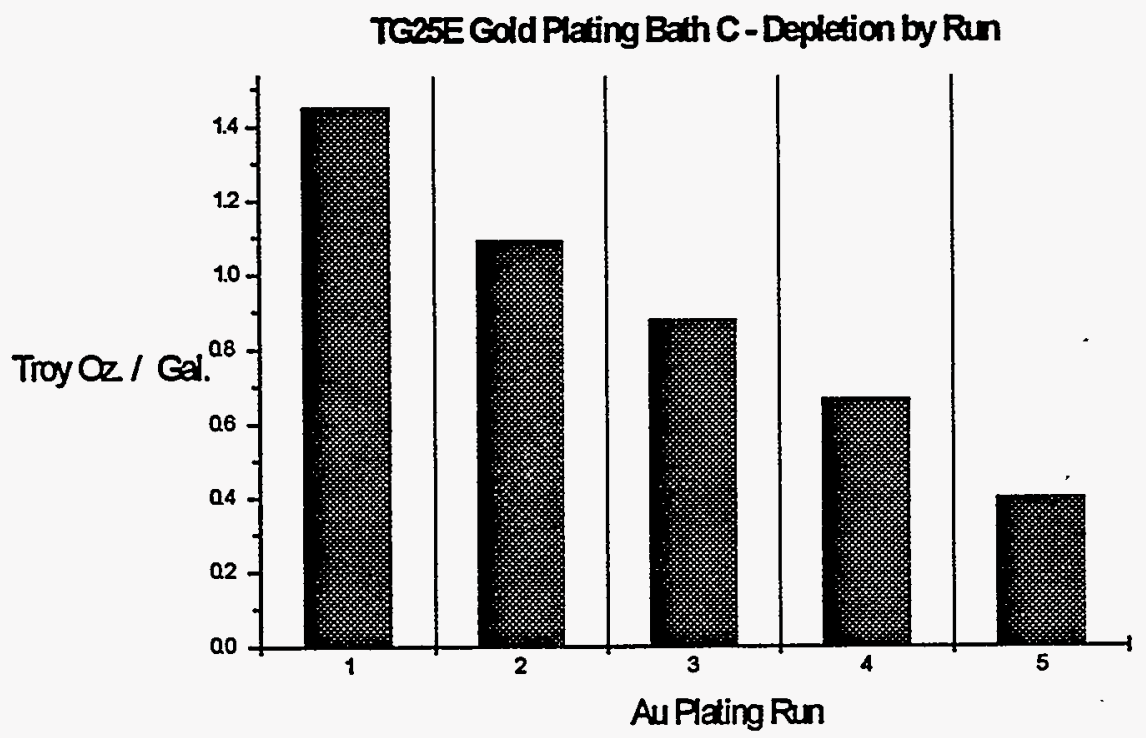

Figure 18. Gold Content of TG25E Sulfite Gold Plating Bath C by Plating Run

The poor efficiency of sulfite plating bath $C$ in depletion testing was accompanied by poor quality gold plated coatings. The coatings were generally foxy brown in appearance and had nodules and slivers attached. Only one plating run had visually acceptable gold, and this was the run (number 2 ) which exhibited higher plating efficiency; however, some nodules were apparent on the plated surface. Specific gravity and $\mathrm{pH}$ of the plating solution dropped somewhat erratically over the range of depletion tests. Specific gravity, as measured by Baume testing, started at 1.098 and was reduced to 1.093 at the end of tests. $\mathrm{pH}$ dropped from 6.80 to 6.77 in the same interval. No other tests were conducted on the plated panels of depletion test $\mathrm{C}$ because of time constraints and the poor quality of the gold coatings.

The poor efficiency and the poor quality plated coatings produced by testing on bath $C$ were indicative of the problems created by precipitates which can occur in sulfite gold 
plating baths. The poor plating efficiency was attributed to the nodules and slivers which formed on the panel surface in an unfiltered bath and then dropped off prior to weigh gain measurements (as the plated panel is rinsed and dried). The suspended particles in the bath were earlier confirmed as being gold; no doubt some of these particles loosely attach themselves to the plated surface, continue to plate, and then drop off during or after plating. The results of the depletion test point out the importance of active filtering as part of the sulfite gold plating operation.

Depletion testing on plating bath $D$ was performed after the active filtration system was added to the plating bath setup. The test setup was identical to that used in bath $C$ testing with the exception of this filtration. However, before testing, all the plating equipment was cleaned and the anodes stripped. The filtration system was tumed on during warm-up and maintained during each plating run. The test procedures used in the depletion tests were as described in the Depletion Test section. Plating tests were conducted through a total of 232 Amp-Minutes at a current density of 3 ASF. As in the prior study, each panel required about 50 Amp-Minutes of plating to produce the 1 mil gold thickness. Testing was initiated with the bath having a measured gold content of 1.45 troy ounces per gallon. Specific Gravity was measured at 1.097 and pH was 6.75.

The results of depletion tests on plating bath $D$ were dramatically different than those for bath C. The efficiency of the first three plating runs was in excess of $90 \%$, and plated panels were generally bright and shiny gold. Plating efficiency for these tests is shown in Figure 19. The initial plating run (number 1) had gold color which was somewhat duller in appearance but was deemed acceptable. The final depletion test run (number 4) produced a reduced efficiency of $69.5 \%$ and a poor plated gold coating. The gold content of bath $D$ at the start of run 4 was 0.39 ounces per gallon. This gold content occurred after three plating runs and appeared to be too low to produce a good electroplated gold coating. A check of the gold content on bath $\mathrm{C}$ during depletion tests showed this gold content was reached after four plating runs. This verified that the efficiencies noted in bath $\mathrm{C}$ testing were indeed low. It lead to the further conclusion that the TG25E sulfite gold process has a minimum gold concentration limit after which the plating efficiency and deposit quality deteriorates. Once this minimum gold concentration limit is reached, the gold deposit becomes granular and loosely adheres to the surface. These granules tend to drop off into the bath which can cause further roughness in the deposit. More work is needed to find the lower limit for the gold concentration and the appropriate concentration window. 


\section{Eficiency of TG25E Gold Plating Bath D}

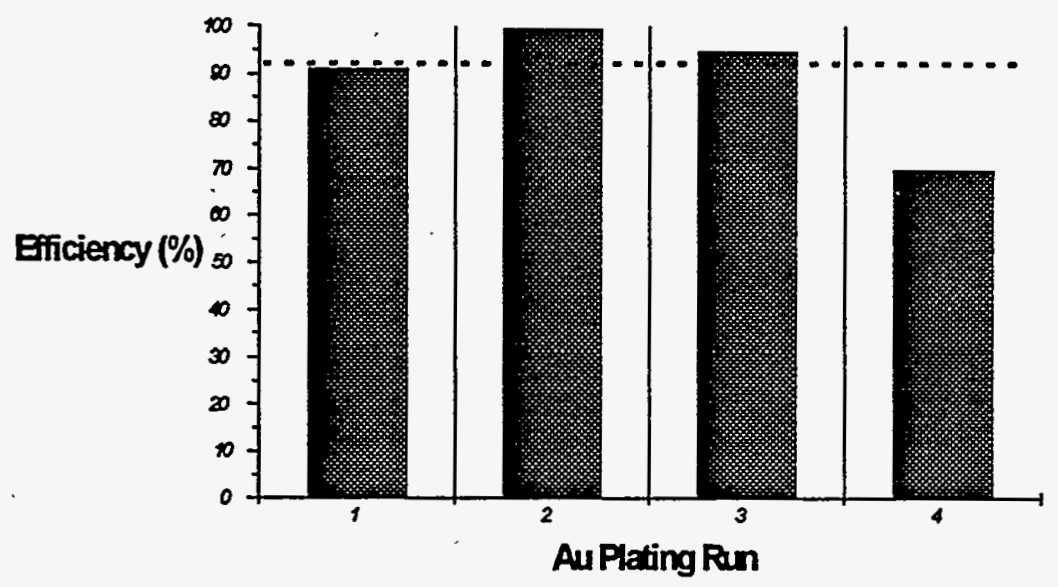

Figure 19. Electroplating Efficiency of Sulfite TG25E Gold Plating Bath D

Visual inspection of plating bath $D$, during and after plating, showed no evidence of suspended particles in the solution. The filter paper was noted to turn a darker color with each plating run. After the initial plating run, the filter was a light tan color and turned to a dark brown color at the end of the final run. Specific gravity and $\mathrm{pH}$ again behaved somewhat erratically over the test runs. It was not known whether this was a true phenomena or a problem with measurement techniques; however, care was taken to perform these measurements accurately and consistently. Specific gravity of the plating solution did show a drop from run 1 (1.097) to run 4 (1.088); however, measurements would fluctuate up and down for the other runs. The $\mathrm{pH}$ actually increased from run $1(6.75)$ to run $4(6.83)$ with similar fluctuations from run to run. Since $\mathrm{pH}$ and specific gravity are variables which are typically used to monitor and permit control of plating solutions, it was disturbing that bath $C$ and $D$ did not behave in a controlled and predictable manner. More understanding of and research in sulfite plating chemistry is needed to permit use of these properties in bath control. The depletion testing did establish that a gold content higher than 0.4 troy ounces per gallon was needed for good plating deposits and that filtering during plating was required. Research toward control and understanding of bath $\mathrm{pH}$ and specific gravity was beyond the scope of this project.

\section{Restoring a Sulfite Gold Plating Bath}

One of the prime considerations in selecting a plating bath is whether it can be restored to usable condition once it has been depleted or drops below specified limits. Plating baths are generally maintained within acceptable limits by monitoring $\mathrm{pH}$, specific gravity, metal content, etc: If a plating bath were to drop below specified limits, it would be necessary to restore the bath such that it was again within limits and electroplated coatings were acceptable. If the bath cannot be restored, it is expensive to replace it and/or it is substituted by another plating bath candidate. One of our final evaluations was to attempt to restore a depleted bath and then analyze the electroplated deposits. This evaluation was performed on sulfite gold plating $D$ which was used in the preceding depletion tests. This sulfite bath had been purchased having a gold content 
of 1.5 troy ounces per gallon, and gold had been reduced to 0.39 at the end of depletion tests. Our plan was to restore the bath to a gold content of 2.0 troy ounces per gallon and then electroplate a test panel. The TG25E plating bath D was adjusted by adding the gold replenisher additives which are provided by Technic Inc.

Discussions with their technical representatives provided information which suggested maintaining gold concentration between 1.5 and 2.0 troy ounces per gallon. Also, it was recommended that the sulfite concentration be increased from 4.0 to 6.0 ounces per gallon. This increases the conductivity of the bath promoting increased efficiency. These suggested changes were made in the evaluation to restore sulfite plating bath $D$ to a usable plating condition. The bath conditions, after restoration, were as shown in Table 7.

\begin{tabular}{|l|c|c|}
\hline Plating Bath Property & Pre-Adjust & After Adjust \\
\hline pH & 6.83 & 6.95 \\
\hline Specific Gravity & 1.088 & 1.161 \\
\hline Gold Content (Troy Oz./Gal.) & 0.39 & 2.0 \\
\hline
\end{tabular}

\section{Table 7. Measured Properties of Plating Bath D After Adjustment}

Electroplating of a $3 \times 3$ inch nickel panel was performed after restoration of plating bath $D$. The test setup was identical to that used in bath $D$ depletion testing with the filtration system turned on during warm-up and maintained during plating. Before testing, all the plating equipment was cleaned and the anodes stripped to ensure clean apparatus. The restoration of the plating bath was a success as determined by plating efficiency and visual appearance of the gold coating. Efficiency was calculated to be $97.07 \%$. The gold plated coating was bright and shiny with no nodules or slivers noted on the surface. The bath remained clear during and after plating with no suspended particles noted in the bath. This result was encouraging in that it provided evidence that the TG25E sulfite gold plating bath could be restored or adjusted to within acceptable plating limits. A further encouraging factor was that efficiency was the second highest recorded in the evaluation. Efficiencies of the sulfite plating baths were typically between 90 to $95 \%$ at the best of plating operations. The $97 \%$ efficiency established a successful restoration and lead to the conclusion that the plating bath operated better at higher gold content for our thick plating application. No further testing was performed on the restored plating bath with the exception of using it for a final test of switch tube plating described in the next section.

\section{SWITCH TUBE PLATING}

The majority of testing and evaluation in the sulfite gold plating study was conducted on flat panel test samples. This was intentional, as these panels yielded better information on the properties of the sulfite gold coatings. However, before concluding the evaluation, it was desired to find out if there were any problems in gold plating a switch tube using the sulfite gold plating bath. The major considerations in plating switch tubes are that the coating produced be uniform and of sufficient thickness to coat all recesses and projections on the tube envelope. Attempts at plating switch tubes using the sulfite gold plating bath are given in this section. 


\section{Initial Switch Tube Plating}

The initial switch tube plating was accomplished using the TG25E sulfite plating bath having a gold content of 1.0 troy ounce per gallon. This was the first bath purchased from Technic for sulfite gold plating evaluations. Fixturing for plating was minimal, as the only pre-plate preparation was to ensure the tube housing and all metal elements of the tube were electrically shorted together. This was done by welding the anode, cathode, and trigger wires together and then soldering them to the copper evacuation tube. A photo of the switch tube prepared for plating is shown in Figure 20. For switch tube plating, the plan was to immerse the tube in the plating solution such that only the tube and a portion of the small copper pipe was covered. An open setup was used for plating with the switch tube being suspended in each plating solution from a plating bar and electrically attached to the power supply by an alligator clip.

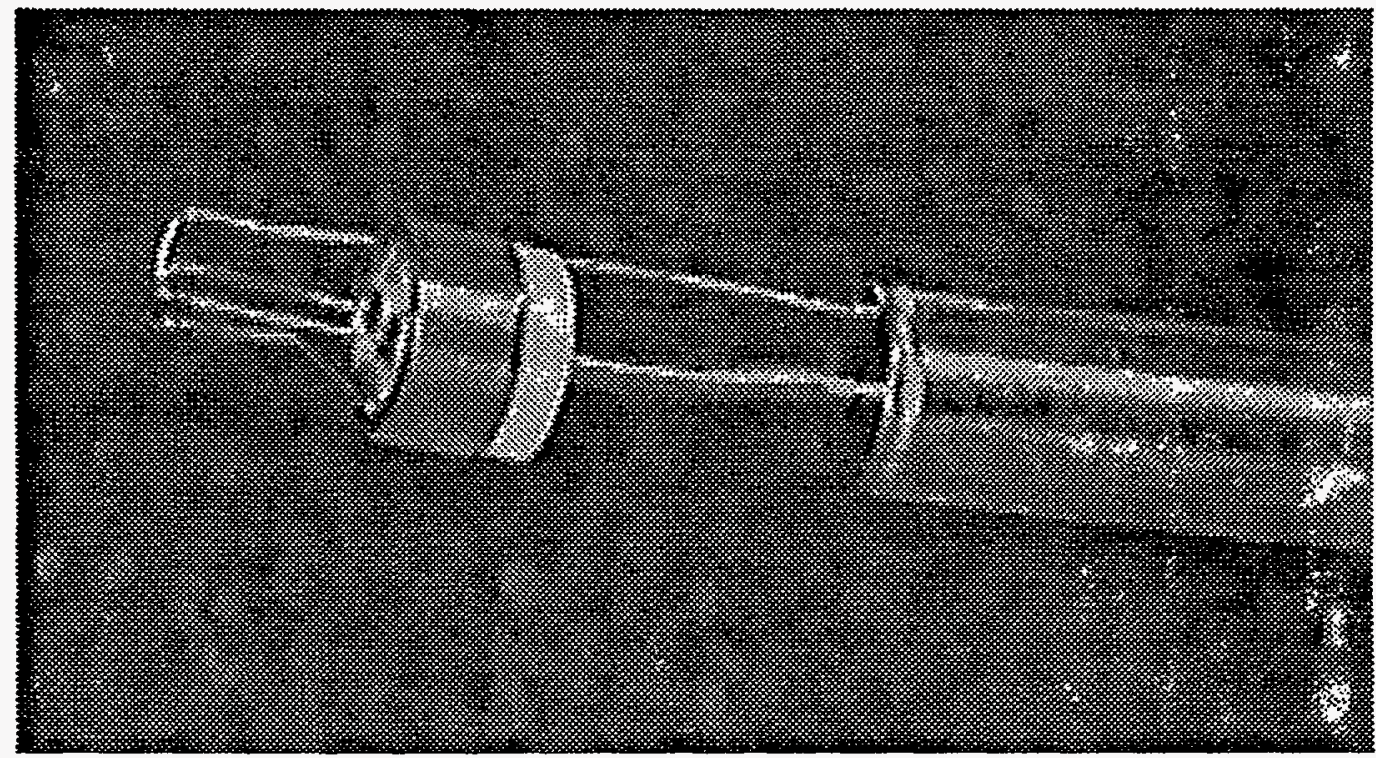

Figure 20. A Switch Tube Which Has Been Prepared for Plating

The initial switch tube gold plating was accomplished in the sulfite gold plating bath without the benefit of any filtering. At the time of plating, the evaluation had not yet established the benefits of plating with active filtration. The complete switch tube plating procedure was used including electrolytic cleaning, nickel strike, electroless nickel plating, gold strike, and finally sulfite gold electroplating (reference Figure 2 processing). Plating parameters in the sulfite gold bath were a plate time of 170 minutes at 23 milliamps for a total of 3.91 amp minutes representing a current density of $3 \mathrm{ASF}$. The plating bath temperature was maintained at $120^{\circ} \mathrm{F}$ during plating with circulation/agitation of plating solution produced by a magnetic spinner bar. Plating bath characteristics of $\mathrm{pH}$ and specific gravity were not checked at the time of switch tube plating but measured 6.8 and 1.080 , respectively, in a prior test.

After plating, the switch tube gold coating was visually inspected and found to be a bright shiny gold. However, many small nodules were noted on the surface and were excessive at corners and projections on the switch tube. To determine gold thickness and uniformity of the coating, the switch tube was sectioned and metallurgical samples 
prepared. The tube was quartered lengthwise and then each quarter mounted to allow gold thickness measurements at different points on the switch tube envelope. A photo of a braze joint in one of the metallurgical samples is shown in Figure 21. As seen in this photo, there are an excessive number of gold nodules which have formed on the metal switch tube surface. This is the typical result of plating in the gold sulfite plating bath without the benefit of active filtration. However, of more importance was the gold coating thickness and uniformity. Each section of the switch tube was inspected with a metallurgical microscope and gold thickness measured at different points on the tube surface. Results of these gold thickness measurements are given in Table 8.

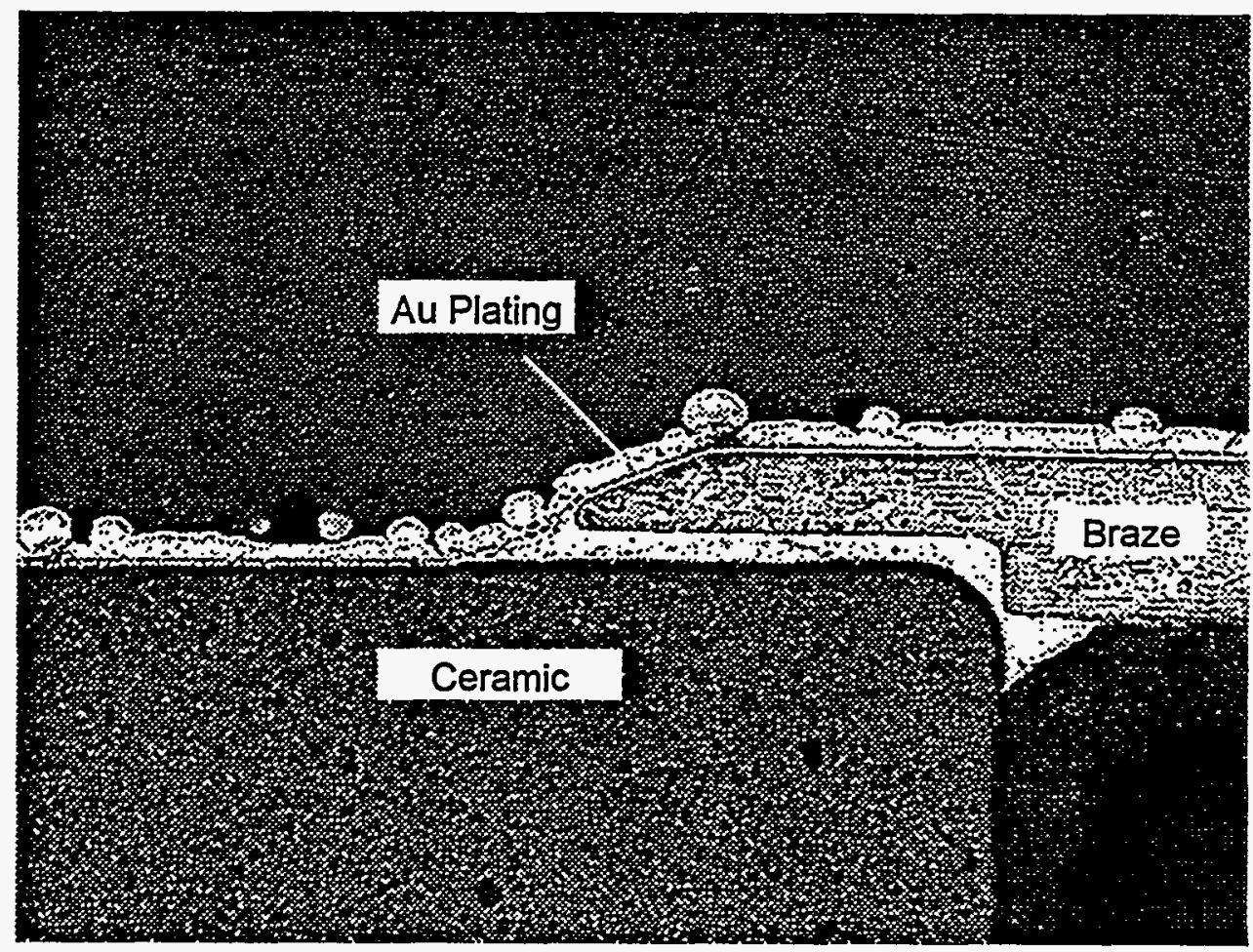

Figure 21. Microphoto of a Switch Tube Braze Joint After Sulfite Gold Electroplating

Gold thickness measurements on the switch tube gold coating showed average thickness to be above the 1 mil required minimum. However, minimum thickness on the brazed area and the side of the tube were below this thickness. As would be expected, at a projection or corner of the tube, the gold measured the maximum thickness being in excess of 2 mils at its thickest point and averaging about 1.6 mils in thickness. Of the 36 measurements taken, only 5 were less than

\begin{tabular}{|c|c|c|c|}
\hline Gold Measure Location & Average & Maximum & Minimum \\
\hline \hline Side of Tube (flat) & 1.35 mils & 1.858 mils & $0.81 \mathrm{mil}$ \\
\hline Corner of Tube & 1.59 mils & 2.63 mils & 1.19 mils \\
\hline Brazed Area & 1.23 mils & 1.76 mils & $0.76 \mathrm{mil}$ \\
\hline
\end{tabular}

Table 8. Gold Thickness Measurements on a Switch Tube Plated in TG25E Sulfite Plating Bath Having a Gold Content of 1.0 Troy Oz. per Gal. 
the 1.0 mil thickness requirement. However, 4 of these low thicknesses were in the braze area where the most protection is needed from gas permeation. Given the overall thickness measurements obtained, we speculated that the gold thickness at the braze areas could be increased with changes in fixturing or solution agitation.

\section{Final Switch Tube Plating}

As a concluding test in the sulfite gold plating evaluation, a switch tube was plated using the restored sulfite gold bath $\mathrm{D}$. The tube preparation for plating and the preplate processing were identical to those used in the initial switch tube plating.

However, there were two important differences in this plating run in contrast to the initial switch tube plating: 1) Active filtration as described in this report was used during plating, and 2) The gold content of the sulfite plating was 2.0 troy ounces per gallon versus 1.0 used in the original plating. Plating parameters in the sulfite gold bath were a plate time of 133 minutes at 23 milliamps for a total of 3.06 amp minutes representing a current density of 3 ASF. The plating bath temperature was maintained at $120^{\circ} \mathrm{F}$ during plating with circulation/agitation of plating solution produced by a magnetic spinner bar combined with the influx of solution returning from the filter pump. Specific gravity and $\mathrm{pH}$ were measured prior to plating at 6.8 and 1.080 respectively.

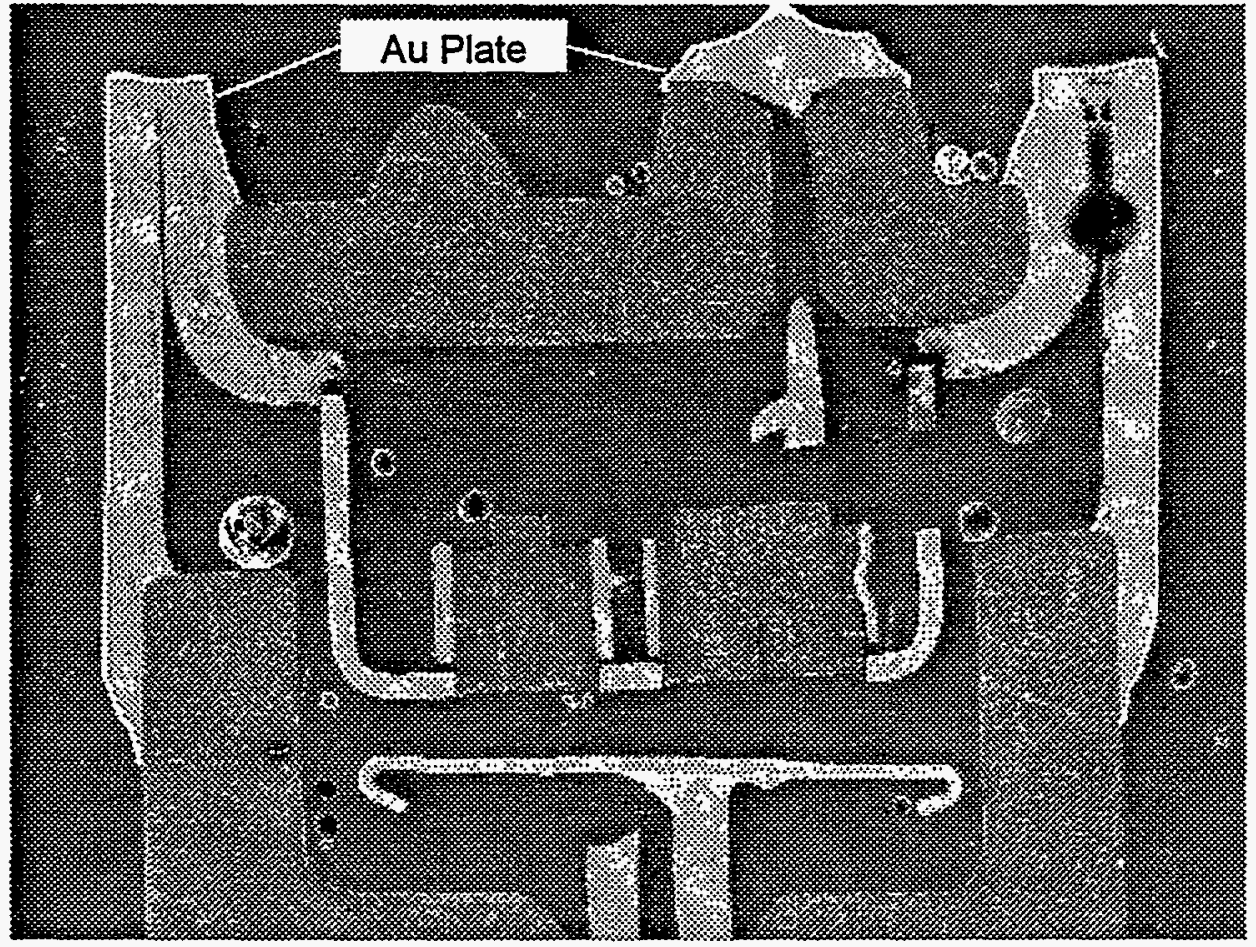

Figure 22. Microphoto of a Cross-Sectioned Switch Tube After Sulfite Gold Electroplating in the Actively Filtered Plating Bath

After plating, the switch tube gold coating was visually inspected and found to be a bright, shiny gold. Only a few, small, gold nodules were noted on the surface of the switch tube. The switch tube was then sectioned, lengthwise, and a metallurgical sample was prepared to permit an analysis of the gold coating thickness and uniformity. 
A photo of the section is shown in Figure 22. Time constraints did not permit the extensive thickness measurements made on the initial tube coating; however, the gold thickness uniformity on this switch tube was similar or possibly superior that on the initial switch tube. The brazed area of the switch tube again appeared to have less gold thickness than other areas on the tube. This aspect of switch tube plating needs to be addressed as further work is planned. The absence of excessive gold nodules and the visibly good, uniform gold coating on the final sulfite gold plating application provided evidence that sulfite gold plating, meeting required specifications, can be used as an alternative to cyanide gold plating on switch tubes.

\section{ACKNOWLEDGGENTS}

A special acknowledgment for the good work by five co-workers who helped make this project possible.

Dan Appel, Department 2566, sample preparation and process consultation. Bob Stokes, Department 2411, photoprocessing, electroplating and inspection. Frank Lucero, Department 2411, evaluation planning, plating applications and equipment setup.

Dale McGuffin, Department 2472, metallurgical sample preparation and gold property measurements.

Barny Ritchie, Department 2472, scanning electron microscopy (SEM) and EDS analysis. 
Distribution:

1 MS-0501

MS-0501

MS-0957

MS-0957

MS-0957

MS-0957

MS-0957

MS-0957

MS-0980

MS-0981

MS-1411

MS-0815

MS-0871

MS-9018

MS-0899

MS-0619

P. J. Wilson, 1565

M. E. Smith, 1565

N. J. Schwentor, 1411-1

K. S. Long, 1411

D. P. Norwood, 1411

F. E. Martinez, 1411

W. Worobey, 1411

R. N. Stokes, 1411

J. Q. Searcy, 1400

J. A. Sayre, 1403

M. J. Cieslak, 1831

F. L. Lucero, 5932

D. B. Appel, 14482

Central Technical Files, 8523-2

Technical Library, 4414

Print Media, 12615

Document Processing, 7613-2

for DOE/OSTI 


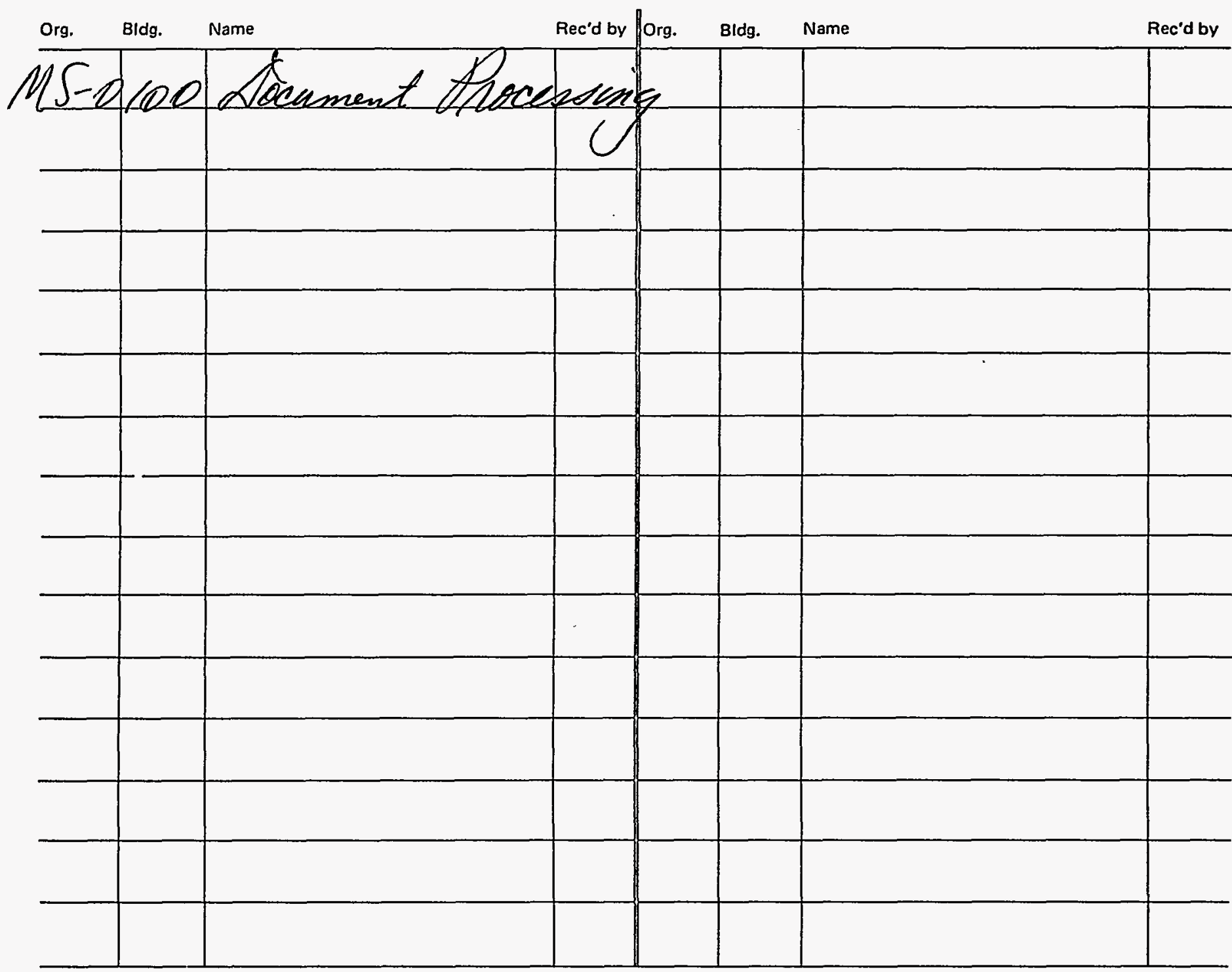

Sandia National Laborarorories 
